\title{
A new source of suprathermal O+ions near the dayside polar cap boundary
}

Article

Published Version

Lockwood, M., Waite, J. H., Moore, T. E., Johnson, J. F. E. and Chappell, C. R. (1985) A new source of suprathermal O+ions near the dayside polar cap boundary. Journal of Geophysical Research, 90 (A5). pp. 4099-4116. ISSN 0148-0227 doi: https://doi.org/10.1029/JA090iA05p04099 Available at https://centaur.reading.ac.uk/38916/

It is advisable to refer to the publisher's version if you intend to cite from the work. See Guidance on citing.

Published version at: http://dx.doi.org/10.1029/JA090iA05p04099

To link to this article DOI: http://dx.doi.org/10.1029/JA090iA05p04099

Publisher: American Geophysical Union

All outputs in CentAUR are protected by Intellectual Property Rights law, including copyright law. Copyright and IPR is retained by the creators or other copyright holders. Terms and conditions for use of this material are defined in the End User Agreement.

\section{www.reading.ac.uk/centaur}

\section{CentAUR}

Central Archive at the University of Reading 
Reading's research outputs online 


\author{
A New Source of Suprathermal $\mathrm{O}^{+}$Ions \\ Near the Dayside Polar Cap Boundary \\ M. LOCKWOOD, 1 J. H. WAITE, JR., T. E. MOORE, \\ J. F. E. JOHNSON, ${ }^{2}$ AND C. R. CHAPPELL
}

Space Science Laboratory, NASA Marshall Space Flight Center, Huntsville, Alabama

\begin{abstract}
A new dayside source of $\mathrm{O}^{+}$ions for the polar magnetosphere is described, and a statistical survey presented of upward flows of $\mathrm{O}^{+}$ions using 2 years of data from the retarding ion mass spectrometer (RIMS) experiment on board DE 1 , at geocentric distances below $3 R_{E}$ and invariant latitudes above $40^{\circ}$. The flows are classified according to their spin angle distributions. It is believed that the spacecraft potential near perigee is generally less than $+2 \mathrm{~V}$, in which case the entire $\mathrm{O}^{+}$population at energies below about $60 \mathrm{eV}$ is sampled. Examples are given of field-aligned flow and of transversely accelerated "core" $\mathrm{O}^{+}$ions; in the latter events a large fraction of the total $\mathrm{O}^{+}$ion population has been transversely accelerated, and in some extreme cases all the observed ions (of all ion species) have been accelerated, and no residual cold population is observed ("toroidal" distributions). However, by far the most common type of $\mathrm{O}^{+}$upflow seen by DE RIMS lies near the dayside polar cap boundary (particularly in the prenoon sector) and displays an asymmetric spin angle distribution. In such events the ions carry an upward heat flux, and strong upflow of all species is present $^{+}$, $\mathrm{He}^{+}, \mathrm{O}^{+}, \mathrm{O}^{++}$, and $\mathrm{N}^{+}$have all been observed with energies up to about $30 \mathrm{eV}$, but with the majority of ions below about $2 \mathrm{eV}$ ); hence, these have been termed upwelling ion events. The upwelling ions are embedded in larger regions of classical light ion polar wind and are persistently found under the following conditions: at geocentric distances greater than $1.4 R_{E}$; at all $K p$ in summer, but only at high $K p$ in winter. Lowenergy conical ions $(<30 \mathrm{eV})$ are only found near the equatorial edge of the events, the latitude of which moves equatorward with increasing $K p$ and is highly correlated with the location of field-aligned currents. The RIMS data are fully consistent with a "mass spectrometer effect," whereby light ions and the more energetic $\mathrm{O}^{+}$ions flow into the lobes and mantle and hence the far-tail plasma sheet, but lower-nergy $\mathrm{O}^{+}$is swept across the polar cap by the convection electric field, potentially acting as a source for the nightside auroral acceleration regions. The occurrence probability of upwelling ion events, as compared to those of low-altitude transversely accelerated core ions and of field-aligned flow, suggests this could be the dominant mechanism for supplying the nightside auroral acceleration region, and subsequently the ring current and near-earth plasma sheet, with ionospheric $\mathrm{O}^{+}$ions. It is shown that the total rate of $\mathrm{O}^{+}$outflow in upwelling ion events (greater than $10^{25} \mathrm{~s}^{-1}$ ) is sufficient for the region near the dayside polar cap boundary to be an important ionospheric heavy ion source.
\end{abstract}

\section{INTRODUCTION}

Since the discovery of $\mathrm{O}^{+}$ions in the magnetosphere by Shelley et al. [1972], much interest has been focused on the ionospheric sources of such ions. The importance of these sources is underlined by the significant and variable $\mathrm{O}^{+}$populations in all magnetospheric regions outside the inner plasmasphere: in the plasma sheet and ring current [Geiss et al., 1978; Lennartsson et al., 1979, 1981; Balsiger et al., 1980; Lundin et al., 1980; Young et al., 1982]; in the plasma mantle and magnetotail boundary layer [Frank et al., 1977; Hardy et al., 1977; Lundin et al., 1980, 1982a, $b$; Candidi et al., 1982]; in the subsolar magnetopause, boundary layer, and magnetosheath [Peterson et al., 1982; Hultqvist, 1983]; and in the outer plasmasphere [Chappell, 1982; T. Roberts, private communication, 1985].

1On leave from Rutherford Appleton Laboratory, Chilton, England.

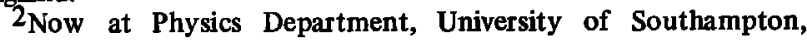
England.

This paper is not subject to U.S. copyright. Published in 1985 by the American Geophysical Union.

Paper number 4A8238.
Upward flows of ionospheric $\mathrm{O}^{+}$ions were observed at energies exceeding $0.5 \mathrm{keV}$ by the ion mass spectrometer on board the S3-3 satellite: such ions display both conical and field-aligned pitch angle distributions and are most frequently found near the auroral oval [Ghielmetti et al., 1978; Collin et al., 1981]. The oval was also found to be the source of ionospheric ions (of unknown mass) of energy greater than $90 \mathrm{eV}$ from a statistical study of data from the electrostatic analyzer on S3-3 [Gorney et al., 1981]. In addition, Shelley et al. [1982], using data from the energetic ion composition spectrometer (EICS) instrument on DE 1 , have observed $\mathrm{O}^{+}$ions near satellite apogee, of energy down to spacecraft potential (a few electron volts), flowing up along polar cap field lines. Yau et al. [1984] have estimated that the occurrence frequency of such upflowing $\mathrm{O}^{+}$(of energy $10 \mathrm{eV}$ to $1 \mathrm{keV}$ ) within the polar cap, although smaller than in the auroral oval, is as large as 0.3 .

The observations described above show that above about $3 R_{E}$, energetic $\mathrm{O}^{+}$ions stream up field lines in the auroral oval and that, in addition, most of the polar cap can contain flows of lower-energy $\mathrm{O}^{+}$ions. This leaves an important gap in our knowledge and understanding of the elevation, in both altitude and energy, of the cold $\mathrm{O}^{+}$ions of the ionosphere to the ions observed in the magneto- 
sphere. The mechanisms by which this is achieved are particularly important to an understanding of the observed variability in the composition of the outflow of ionospheric ions at high latitudes. The retarding ion mass spectrometer (RIMS) experiment on DE 1 offers a unique opportunity to study these mechanisms, being the first mass-resolving instrument to cover the required altitude range and observe $\mathrm{O}^{+}$ions of energy right down to and below spacecraft potential. Waite et al. [1985] have observed, using RIMS, low-energy $\mathrm{O}^{+}$ions which were flowing upward along polar cap field lines between 2 and $4 R_{E}$ during high magnetic activity. From electric field measurements by the retarding potential analyzer-ion drift meter (RPA-IDM) instrument on board DE 2, Waite et al. mapped the ionospheric source of such ions for two orbits of DE 1 and found it to lie near the dayside polar cap boundary in both cases.

Axford [1968] had suggested $\mathrm{O}^{+}$ions could be added to the ionospheric light ion outflow at high latitudes ("the polar wind") by large photoelectron fluxes. However, modeling by Banks and Holzer [1969] predicted total ion outflows (all species and normalized to an altitude of $1000 \mathrm{~km}$ ) of about $10^{8} \mathrm{~cm}^{-2} \mathrm{~s}^{-1}$, of which only about $0.1 \%$ would be $\mathrm{O}^{+}$ions, these limits being set by the gravitational binding of $\mathrm{O}^{+}$ions, which then in turn limit light ion outflows by Coulomb drag. Various mechanisms have been proposed to allow additional $\mathrm{O}^{+}$to overcome gravitational binding: transverse or parallel acceleration at low altitudes [Moore, 1980; Lockwood, 1984], very high electron temperatures [Barakat and Schunk, 1983], transient plasma expansion [Singh and Schunk, 1982], and high-altitude acceleration mechanisms [Barakat and Schunk, 1984]. The presence of accelerated ions, in addition to the "classical" cold polar wind, has been confirmed by high-altitude observations by the high altitude plasma instrument (HAPI) instrument on board DE 1 [Gurgiolo and Burch, 1982].

A steady state enhanced outflow of $\mathrm{O}^{+}$gives an enhanced total ion outflow. Thermal fluxes which were an order of magnitude larger than the $10^{8} \mathrm{~cm}^{-2} \mathrm{~s}^{-1}$ predicted by Banks and Holzer have been observed at very low altitudes in the topside ionosphere by Lockwood and Titheridge [1981], Lockwood [1982, 1984], Heelis et al. [1984], and Farmer et al. [1984]. Such large, low-altitude fluxes indicate extensive filling of the topside ionsophere or enhanced thermal ion escape into the magnetosphere. Lockwood and Titheridge [1981] and Lockwood [1982] have shown such large flows occur in a broad range of latitudes around the polar cap boundary on both the dayside and nightside, and Farmer et al. [1984] and M. Lockwood (unpublished manuscript, 1984) have found that they are associated with enhanced geomagnetic activity (consistent with the polar cap flows observed by Waite et al. [1985]). Heelis et al. [1984] have studied two cases of exceptionally large flux $\left(>10^{10} \mathrm{~cm}^{-2} \mathrm{~s}^{-1}\right)$, observed at an altitude of 900 $\mathrm{km}$ by $\mathrm{DE} 2$, and found them to be associated with intense upward field-aligned current and both parallel and transverse ion acceleration.

In this paper, a large number of data, taken when DE 1 was near perigee $\left(<3 R_{E}\right)$ by the RIMS experiment, are surveyed. Examples are found of low-energy, upflowing $\mathrm{O}^{+}$ which are consistent with one or more of the proposed ionospheric escape mechanisms: transversely accelerated $\mathrm{O}^{+}$ ions (indicating low-altitude transverse acceleration); $\mathrm{O}^{+}$ field-aligned flows (indicating low-altitude parallel acceleration by either ambipolar or current-driven electric fields); however, by far the most common pitch angle distribution of escaping $\mathrm{O}^{+}$is found to be a new type of $\mathrm{O}^{+}$flow event which shows evidence for both perpendicular and parallel ion acceleration below the satellite and is found exclusively in the lower latitudes of the dayside polar cap. All species of ions are observed to move upward during these events, with an upward heat flux.

\section{OBSERVATIONS}

This paper presents a statistical survey of observations of upward flows of $\mathrm{O}^{+}$ions made by the RIMS instrument at low altitudes. A full description of the RIMS instrument is given by Chappell et al. [1981]. Only data for geocentric distances smaller than 3 earth radii are included here $\left(r / R_{E}<3\right)$, but observations are not always available for all altitudes down to the DE 1 perigee of $675 \mathrm{~km}$. This is because at the lowest altitudes the plasma densities are generally greatest and, in order to protect the instrument from prolonged excessive counting rates, it is shut off.

The observations used in this study were made in a 2-year period between October 19, 1981, and October 18, 1983. Although a large fraction of the data for the first of these 2 years has been processed, the same is not true for the second year. All available data from this period were used in this study; this includes data from a variety of observational modes which sample $\mathrm{O}^{+}$ions. Flows of $\mathrm{O}^{+}$, moving upward along geomagnetic field lines, were classified according to their pitch angle distributions, determined from the radial sensor head, as it rotates through a full range of pitch angles in each 6-s satellite spin period. On November 25, 1981, the RPA on the radial head failed, and at subsequent times, the retarding potential stayed set at zero. Consequently, energy information from the radial head was considerably degraded in resolution for $\mathrm{O}^{+}$and completely lost for the light ions. RPA scans were only obtained for the two end, or $Z$, heads, which detect ions moving roughly transverse to the geomagnetic field (within a solid angle of near $2 \mathrm{sr}$ at $2 \mathrm{eV}$ energy and $0.7 \mathrm{sr}$ at $10 \mathrm{eV}$, for $\mathrm{O}^{+}$ions). Hence, for field-aligned flows or highly folded conical distributions, no rigid classification of $\mathrm{O}^{+}$flows by their energy range was possible. Classification by pitch angle distribution alone does have the advantage of allowing data to be utilized from both the "survey" and "mass scan" modes of operation. In the survey mode the ion species $\mathrm{H}^{+}, \mathrm{He}^{+}, \mathrm{O}^{+}, \mathrm{He}^{++}$, and $\mathrm{O}^{++}$were monitored (and following the failure of the radial head RPA, $\mathrm{N}^{+}$was added to this list without loss of resolution or information). In the mass scan mode, all ion masses between about 4 and 32 amu were scanned, but no energy information was obtained.

Data for all four possible bias settings for the aperture rings surrounding the detectors [Chappell et al., 1981] $(0,2,4$, or $8 \mathrm{~V}$ negative, relative to spacecraft potential) were included in this statistical survey. At the lowest altitudes, the spacecraft generally has a negative potential, due to ambient plasma densities in excess of about 200 $\mathrm{cm}^{-3}$ (R. H. Comfort, private communication, 1984). In such cases, for any of the aperture biases, RIMS should be sampling the entire $\mathrm{O}^{+}$ion population from about $60 \mathrm{eV}$ down to zero energy. However, it is still possible in other cases that RIMS may not have detected the lowest-energy 
TABLE 1. Numbers of 1-min Integrated Samples for 90-day Periods Around the Solstices and Equinoxes and for All Days of the Year

\begin{tabular}{|c|c|c|c|c|}
\hline & \multicolumn{4}{|c|}{ Local Time } \\
\hline & $0000-0600$ & $0600-1200$ & $1200-1800$ & $1800-2400$ \\
\hline \multicolumn{5}{|c|}{$r / R_{E}=1-2$} \\
\hline $\begin{array}{l}\text { Summer } \\
\text { Spring } \\
\text { Winter } \\
\text { Fall } \\
\text { All days }\end{array}$ & $\begin{array}{l}105 \\
182 \\
407 \\
288 \\
993\end{array}$ & $\begin{array}{r}946 \\
279 \\
227 \\
373 \\
1843\end{array}$ & $\begin{array}{l}240 \\
232 \\
118 \\
142 \\
732\end{array}$ & $\begin{array}{r}219 \\
63 \\
254 \\
581 \\
1149\end{array}$ \\
\hline \multicolumn{5}{|c|}{$r / R_{E}=2-3$} \\
\hline $\begin{array}{l}\text { Summer } \\
\text { Spring } \\
\text { Winter } \\
\text { Fall } \\
\text { All days }\end{array}$ & $\begin{array}{r}337 \\
39 \\
52 \\
343 \\
771\end{array}$ & $\begin{array}{r}441 \\
76 \\
251 \\
918 \\
1686\end{array}$ & $\begin{array}{r}624 \\
835 \\
873 \\
0 \\
2332\end{array}$ & $\begin{array}{r}1165 \\
355 \\
1214 \\
1909 \\
4772\end{array}$ \\
\hline
\end{tabular}

ions. This would tend to occur at greater altitudes and would be caused by positive spacecraft potentials in excess of the magnitude of the aperture bias which was in use. At $r / R_{E}<3$, the velocity of the satellite is greater than 5 $\mathrm{km} \mathrm{s}^{-1}$, and the "RAM energy" for $\mathrm{O}^{+}$ions (the energy of an $\mathrm{O}^{+}$ion in the reference frame of the spacecraft, due to the spacecraft's motion) is greater than $2 \mathrm{eV}$. Hence, RIMS will not detect the lowest-energy $\mathrm{O}^{+}$at $r / R_{E}<3$, if the spacecraft potential is positive and exceeds the magnitude of the aperture bias by at least $2 \mathrm{~V}$.

Ion count rates were accumulated over 1-min intervals, to average out statistical fluctuations and to effect data reduction, before the spin angle distributions were classified (see section 3). Each such distribution was considered as one sample, made at the location (in local time, height, and invariant latitude) of the DE 1 spacecraft at the center of the 1-min period, plus and minus errors given by its locations at the extremes of that period. In the 2 years studied, a total of 14,278 such samples were obtained for invariant latitudes greater than $40^{\circ}$ in either hemisphere at $r / R_{E}<3$.

The highly elliptical orbit of DE 1 , the rate of drift of the line of aspides $\left(0.328^{\circ}\right.$ per day; i.e., from one pole to the other is roughly 18 months), and the rate of westward rotation of the orbital plane ( 1 hour of local time per 15.4 days, i.e., 24 hours in about 12 months) give an uneven local time average of the topside high-latitude ionsophere during the different seasons. Table 1 lists the number of samples obtained in four local time quadrants at invariant latitudes exceeding $40^{\circ}$ and in altitude ranges $1-2 R_{E}$ and 2-3 $R_{E}$. Values are given for 90-day periods around the solstices and equinoxes and for all days of the year. In the lower height range, coverage is generally poorest in the afternoon sector; whereas in the greater height range it is worst in the postmidnight sector. The low sample numbers for the equinoxes are not generally a problem, as fall and spring data can often be combined. This leaves the following bins for which there are notably few samples: in the postmidnight sector, at the higher altitudes in winter and at the lower altitudes in summer, and in the winter afternoon sector at low altitudes. Otherwise sample numbers exceed 200 for the other bins. The majority of samples are for moderate or low levels of geomagnetic activity with $K p$ values falling in the range $0<K p<3$ o for $49 \%$ of the samples, in the range $30<K p<6$ for $46 \%$ of the samples, and in the range $60<K p<90$ for only $5 \%$ of the total of 14,278 . The number of samples decreases with altitude, with $38 \%$ at $2.5 \leqslant r / R_{E}<3.0,29 \%$ at $2.0 \leqslant r / R_{E}<2.5$, $23 \%$ at $1.5 \leqslant r / R_{E}<2.0$, and only $10 \%$ at $r / R_{E}$ below 1.5 .

\section{Classification OF $\mathrm{O}^{+}$ION FlOWS}

Plates 1-3 show color-coded spectrograms of data recorded by the RIMS instrument and are given as examples of the three types of upward $\mathrm{O}^{+}$flow observed.

\subsection{Field-Aligned $\mathrm{O}^{+}$Flow}

Plate 1 shows an hour of data recorded on November 8,1981 , between 1600 and 1700 UT, which displays fieldaligned flow of $\mathrm{O}^{+}$. The top panel shows the $\mathrm{O}^{+}$spin-time spectrogram; the lower panel is for $\mathrm{H}^{+}$. The mean number of counts during an accumulation period $(12 \mathrm{~ms})$ is coded according to the scale shown to the left of the figure; the count rate per sample is approximately proportional to the integral number flux of that ion species; for $\mathrm{O}^{+}$, the proportionality constant is roughly $4.4 \times 10^{4}$. The dashed and dotted lines show the upward and downward field-aligned directions, respectively. Between 1600 and $1635 \mathrm{UT}$, the satellite is above $3 R_{E}$, and $\mathrm{O}^{+}$flow along the upward field-aligned direction is observed, with only weak $\mathrm{H}^{+}$ flow. This is an example of the high-altitude $\mathrm{O}^{+}$flows within the polar cap as studied by Waite et al. [1985]. Note the effect of variations in a large convection electric field which causes the $\mathrm{O}^{+}$spin distribution to peak in a direction which is slightly removed from the field-aligned direction. As the satellite descends in both altitude and invariant latitude in the premidnight sector, ions are found between the upward field-aligned and RAM directions (1635-1647 UT). Such spin angle distributions still reveal field-aligned upflow, but with velocities comparable to the spacecraft RAM velocity. When the spacecraft's RAM direction is aligned exactly perpendicular to the geomagnetic field, convection alone cannot cause a shift of the distribution from the RAM direction (it can only modify the magnitude of the shift which a field-aligned flow causes). Over the polar cap the DE 1 orbit is always at approximatley $90^{\circ}$ to the magnetic field, so any detectable 
shift from the RAM direction reveals a field-aligned flow.

On leaving the nightside polar cap, the satellite passes through a region of relatively low $\mathrm{O}^{+}$density before entering the plasmasphere at about 1654 UT. Within the plasmasphere, the $\mathrm{O}^{+}$spin distribution is symmetric about the RAM direction. Such a distribution is indicative of a cold, isotropic ion population. When the $\mathrm{O}^{+}$density is high, a large flux can be carried by ions moving with low velocities. If these velocities are small compared to the spacecraft RAM velocity, the shift of the center of the spin distribution from the RAM direction may not be resolved. For this reason, field-aligned $\mathrm{O}^{+}$flows within the plasmasphere and at low altitudes (where the $\mathrm{O}^{+}$density is high) may have been omitted in this study. A sample was classified as showing field-aligned flow when a shift of the median of the spin distribution from the RAM direction could be resolved $\left(>15^{\circ}\right)$ but there was not detectable asymmetry in the spin distribution.

\subsection{Transversely Accelerated Core $\mathrm{O}^{+}$Ions}

Plate 2 shows data from a pass on April 25, when DE 1 again left the nightside polar cap, but this time ascending in height as it did so. In this case, no $\mathrm{O}^{+}$flow is detected until 0508, when transversely accelerated ions are detected in all observed ion species $\left(\mathrm{O}^{+}, \mathrm{H}^{+}, \mathrm{He}^{+}\right.$, and $\left.\mathrm{O}^{++}\right)$. These persist until the end of data at 0517 . The pitch angle peaks move toward the field-aligned direction during this period. When first observed, the transversely accelerated $\mathrm{O}^{+}$ions peaked at pitch angles near $90^{\circ}$, indicating that the satellite (near $2 R_{E}$ ) is close to the transverse acceleration region (or a mirroring height, if the $\mathrm{O}^{+}$ions are also moving downward). Later in the event, however, the ion spin distributions are folded, showing the majority of the ions to have an upward field-aligned component. Note that in this example, all the ions observed by RIMS have been transversely accelerated after $0508 \mathrm{UT}$ : there is no cold rammed population observed. A sample was classified as showing transversely accelerated "core" ions (TACI) if the spin angle distribution showed resolvable peaks on both sides of the upward field-aligned direction at any cone angle between $0^{\circ}$ and $90^{\circ}$. Hence, this classification includes pancake distributions, conics, and toroidal distributions [see Moore et al., 1985].

The adjective "core" has been applied to these TACI events to distinguish them from the transversely accelerated ion (TAI) events discussed by Klumpar [1979, 1981], of which the TACI events are a subset. This is firstly because the TAI events observed using the ISIS 2 electrostatic analyzer included possible ion species other than $\mathrm{O}^{+}$. Secondly the definition of a TACI event requires a sufficient portion of the total $\mathrm{O}^{+}$ion population be moving transverse to the geomagnetic field, so that they are not obscured in the DE 1 RIMS, 15-eV-bandwidth observations by an unheated cold distribution core. Such obscuration would not have occurred for the ISIS 2 observations because of the $5-\mathrm{eV}$ threshold and the narrower differential response of the electrostatic analyzer. Plate 2 is an example of a TACI event where the entire core has been transversely accelerated, i.e., a toroidal distribution event. In other cases some cold core may remain unheated but is insufficient to conceal the transversely heated ions in the RIMS data.

\subsection{The New $O^{+}$Ion Source, Upwelling Ions}

The results of this paper will show that for low-energy $\mathrm{O}^{+}$ions, the flows described in the previous two subsections are comparatively rare at low altitudes, compared to a third kind of $\mathrm{O}^{+}$flow. The spin angle behavior of these events is more complex than that of either field-aligned flows or transversely accelerated core ions, displaying the effects of both parallel and perpendicular ion acceleration. Plate 3 shows a pass from the premidnight sector to the morning sector, across the polar cap. As the satellite descends, in invariant latitude and altitude, the $\mathrm{O}^{+}$distribution (Plate $3 a$ ) is initially symmetric about the RAM direction but at $1120 \mathrm{UT}$ becomes asymmetric toward the upward field-aligned direction. The asymmetry grows until 1126, when there is a sharp cutoff and a return to a rammed $\mathrm{O}^{+}$distribution. This feature is always present in all ion species present (in this example, $\mathrm{H}^{+}, \mathrm{He}^{+}$, and $\mathrm{O}^{+}$; in other events, $\mathrm{O}^{++}$and $\mathrm{N}^{+}$have been observed to behave similarly) with the light ions often appearing in the lowerlatitude half of the $\mathrm{O}^{+}$event and extending slightly equatorward of the $\mathrm{O}^{+}$event (see Plates $3 a$ and $3 b$ ). The asymmetry in the spin angle distribution can be detected between 1120 and 1126 UT as it grows toward the upward field-aligned direction. Note that the distribution to the downward side of the RAM direction is relatively constant during the event, but is slightly shifted, particularly for the period 1123-1124 UT. At latitudes either side of the event, light ions $\mathrm{H}^{+}$and $\mathrm{He}^{+}$show upward field-aligned flow, whereas no flow of $\mathrm{O}^{+}$is detected; this is qualitatively consistent with the original polar wind theory of Banks and Holzer [1969] in which the $\mathrm{O}^{+}$is gravitationally bound.

The spin angle-time spectrograms in Plates 1 and 3 are for all energies detected by RIMS (a range of the RPA step number 0 to 1000 ). For $\mathrm{O}^{+}$at the altitudes studied here, this is an energy range of about -2 to $60 \mathrm{eV}$, above spacecraft potential minus the aperture bias. Plates $3 c$ and $3 d$ show the concurrent energy-time spectrograms for $\mathrm{O}^{+}$from the two $Z$ heads looking parallel and antiparallel to the spacecraft spin axis and perpendicular to the geomagnetic field. During the low-latitude half of the event, the $Z$ heads observe a large number of ions with peak energies which increase with decreasing latitude to near $30 \mathrm{eV}$ at the sharp, low-latitude edge of the event. Such ions would be moving within a solid angle of about $2 \mathrm{sr}$, about the normal to the magnetic field.

The RPA on the radial head of RIMS failed on November 25,1981 . Subsequent to this time the radial head functions as a differential flux instrument for $\mathrm{O}^{+}$, but with poor energy resolution $(\sim 15 \mathrm{eV})$. This is because the deflection angle and the preacceleration of the RIMS select a range of energies (about $15 \mathrm{eV}$ wide) which is stepped upward in energy as the RPA step number is increased. As a result the RPA step number is approximately proportional to $\mathrm{O}^{+}$ion energy. In the following section no attempt has been made to deconvolve the instrument response for the data for $\mathrm{O}^{+}$recorded after November 25 , 1981 , and they are sorted according to RPA step number. However, approximate energy ranges can be ascribed to an RPA step number range by assuming the $\mathrm{O}^{+}$response function is $15 \mathrm{eV}$ wide and centered on the energy of the RPA step number.

Figure $1 a$ shows the spin angle distributions observed 

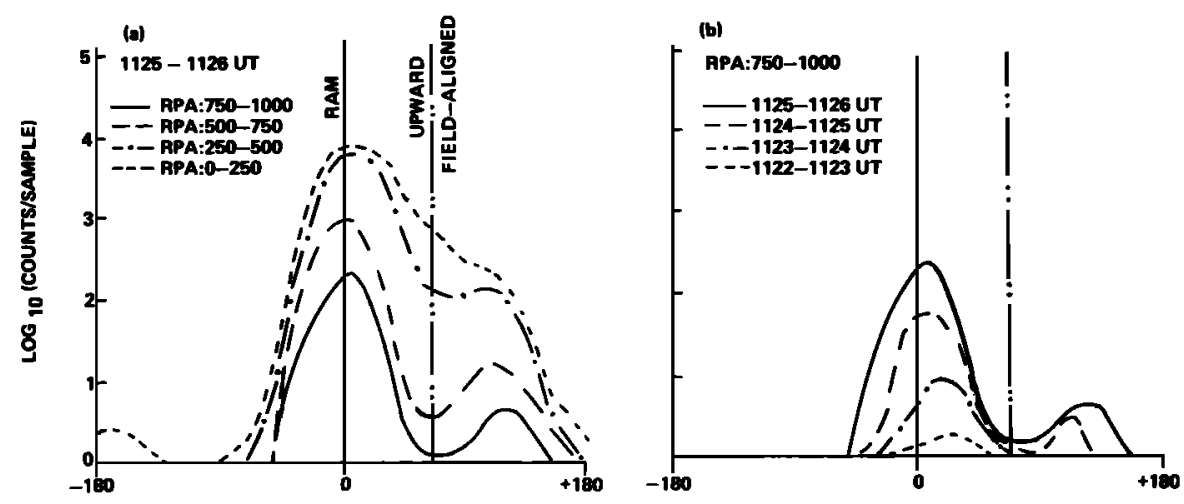

SPIN ANGLE (DEG.)

Figure 1. Spin spectra in 1-min periods of the event shown in Plate 3 for (a) four ranges of the RPA step number at 1125-1126 UT and $(b)$ the 750-1000 range of RPA step numbers during 1-min periods between 1125 and 1123 UT. The four RPA ranges approximately correspond to energy ranges of $0-20,5-32,18-45$, and $30-57$ eV above spacecraft potential.

between 1125 and 1126 UT on April 15, 1982 (the lowlatitude edge of the event shown in Plate 3), for four ranges of the radial head RPA step number. For the lowest RPA step number range $(0-250)$, approximately corresponding to $\mathrm{O}^{+}$energies of $0-30 \mathrm{eV}$ above spacecraft potential, the distribution is asymmetric, and very similar to that for all RPA steps integrated together, the bulk of the plasma being detected in this range; however, for the highest RPA step number range $\left(750-1000\right.$, approximate $\mathrm{O}^{+}$energy range 30-57 eV above spacecraft potential), there is an asymmetric conical distribution with a clear minimum along the upward field-aligned direction. Figure $1 b$ plots the spin angle distributions for the 750-1000 RPA step number range for various integration periods during the event. Conical ions are only found between 1124 and 1126 UT (at invariant latitudes $76.1^{\circ}$ to $79.1^{\circ}$ ); hence, they are in the lower-latitude part of the event which extends from $\Lambda=76.1^{\circ}$ to $83.7^{\circ}$. Plates $3 c$ and $3 d$ show that at these times the $Z$ heads detect ions of energy up to about $30 \mathrm{eV}$ (relative to spacecraft potential minus aperture bias) but with an RPA curve knee near $10 \mathrm{eV}$. For such low energies, the spacecraft RAM velocity will distort the spin distribution, making it asymmetric with more counts in the conic lobe which is closest to the RAM direction [see Sharp et al., 1983]. The $Z$ heads also set a lower limit of about $2 \mathrm{eV}$ for the energy of the transversely accelerated ions observed embedded within the upwelling ion event.

Consider ions of mass $m_{i}$ and charge state $q$ observed by RIMS at a geocentric distance $r$ to have an energy $E_{T}(r)$ (in electron volts); having undergone scatter-free motion following transverse acceleration (at $r_{\mathrm{o}}$ ), the pitch angle will be

$$
\begin{aligned}
\theta(r)= & \sin ^{-1}\left\{\frac { B ( r ) } { B ( r _ { \mathrm { o } } ) } \left(1-\frac{q \Delta V}{\left(E_{\left.T^{(r)+\phi_{s}}-V_{a}\right)}\right.}+\frac{m_{i} g_{s} R_{E}^{2}}{e r\left(E_{T^{2}}(r)+\phi_{s}-V_{a}\right)},\right.\right. \\
& {\left.\left.\left[\frac{r}{r_{\mathrm{o}}}-1\right]\right)\right\}^{1 / 2} }
\end{aligned}
$$

where $\Delta V$ is the potential difference between $r$ and $r_{0}, \phi_{S}$ is the spacecraft potential, $V_{a}$ is the aperture bias setting (in volts), $g_{s}$ is gravitational acceleration at the earth's surface (radius of curvature $R_{E}$ ), $B$ is the geomagnetic field, and $e$ is the electronic charge. Using equation (1), $r_{\mathrm{O}}$ can be iterated to give the observed pitch angle for a model geomagnetic field, and assumed values of $\Delta V$ and $\phi_{S}$. For 1125-1126 UT, the ions observed in the RPA step range $750-1000$ peak at a pitch angle of $118^{\circ} \pm 5^{\circ}$. Assuming adiabatic, scatter-free motion from source to satellite, a dipole geomagnetic field, and zero spacecraft potential gives a value for $r_{0}$ of $1.52 R_{E}( \pm 0.06)$ for the "knee" transverse ion energy of $10 \mathrm{eV}$, corresponding to an altitude of $3300 \mathrm{~km}( \pm 350)$. For $2 \mathrm{eV}$ ions, a minimum estimate for the lowest-energy conical ions, the gravitational effect is more important (and tends to broaden the conic for a given $r$ and $r_{o}$, particularly in the case of heavy ions): an $r_{0}$ of $1.47 R_{E}( \pm 0.07)$ is found, corresponding to an altitude of $3020 \mathrm{~km}( \pm 440)$. The uncertainties in these source heights, which are due to the resolution of the spin angle distribution peaks, are greater than the errors due to the assumed value for $\phi_{s}$. The presence of any positive $\Delta V$, which accelerates ions upward, would mean that the true source region would be located above these estimates.

As discussed by Moore et al. [1985], the asymmetry in the spin distribution indicates an upward heat flux is carried by the ions which are hence upwelling in response to ion heating below the satellite. Hence, these asymmetric spin distribution events will henceforth be referred to as upwelling ion events. Using approximate estimates for the density and parallel $\mathrm{O}^{+}$temperature for the event shown in Plate 3(of $100 \mathrm{~cm}^{-3}$ and $3 \mathrm{eV}$, respectively), we find the heat flux carried by $\mathrm{O}^{+}$ions to be in excess of $3 \times 10^{-4}$ erg $\mathrm{cm}^{-3} \mathrm{~s}^{-1}$, which is the minimum value required to cause a detectable asymmetry in the spin distribution.

\section{OCCURRENCE Probabilities OF the VARIOUS CLASSIFICATIONS OF $\mathrm{O}^{+}$ION FLOWS}

Each of the 14,278 samples described in section 2 were classified according to the $\mathrm{O}^{+}$spin angle distribution as having one of the following forms: (1) asymmetric spin angle distribution and upward flow (upwelling ions); (2) symmetric spin angle distribution, with the mean value 
shifted from the RAM direction toward the upward fieldaligned direction (field-aligned upflow); (3) upgoing transversely accelerated core ions; or (4) no detectable ion flow. The occurrence probabilities of the first three classes $\left(f_{u}, f_{a}\right.$, and $f_{c}$, respectively) were then evaluated for various local time, invariant latitude, $K p$, and seasonal bins, along with the standard deviation.

\subsection{Invariant Latitude-Local Time Variations}

The occurrence probabilities of these events are shown in Plate 4 in local time-invariant latitude plots for all $K p$, all days of the year, and all geocentric distances below $3 R_{E}$. For the 2-hour local time and $2.5^{\circ}$ invariant latitude bins used, occurrence probabilities for the upwelling heated $\mathrm{O}^{+}$flows, $f_{u}$, of up to 0.6 are observed. By comparison, the occurrence frequency of field-aligned flows, $f_{a}$, has a maximum of 0.3 for these size bins, and that of transversely accelerated core ions (TACI's), $f_{c}$, has a maximum of 0.2 .

Very few bins show $\mathrm{O}^{+}$TACI probabilities $f_{c}$ which exceed 0.04 , and those that do are generally at auroral latitudes. Hence the occurrence frequencies of $\mathrm{O}^{+}$TACI's, as observed by RIMS, are considerably smaller than the probability of low-altitude TAI's as seen by ISIS 2 at 1400 $\mathrm{km}$ [Klumpar, 1979] and of large thermal $\mathrm{O}^{+}$flows seen in the topside ionosphere [Lockwood, 1982]. Both of these latter two types of events had occurrence probabilities of over 0.5 in the nightside auroral oval, and both were attributed to the effects of low-altitude transverse acceleration of $\mathrm{O}^{+}$. There are several effects which may have caused the occurrence frequency of $\mathrm{O}^{+} \mathrm{TACI}$ 's, as observed in minute integrations of RIMS data, to be lower than its true value. First, if ions are accelerated to energies in excess of about $60 \mathrm{eV}$, they will no longer be detected by RIMS, and second, as data have been integrated into 1-min periods, short-lived events may have been smoothed out.
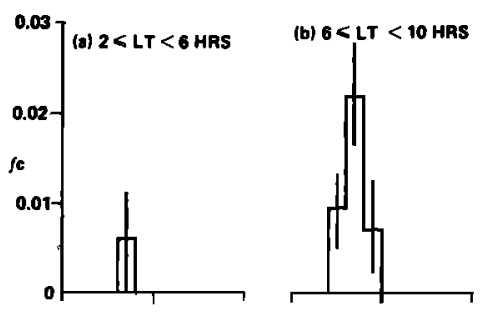

(c) $10<$ LT $<14$ HAS
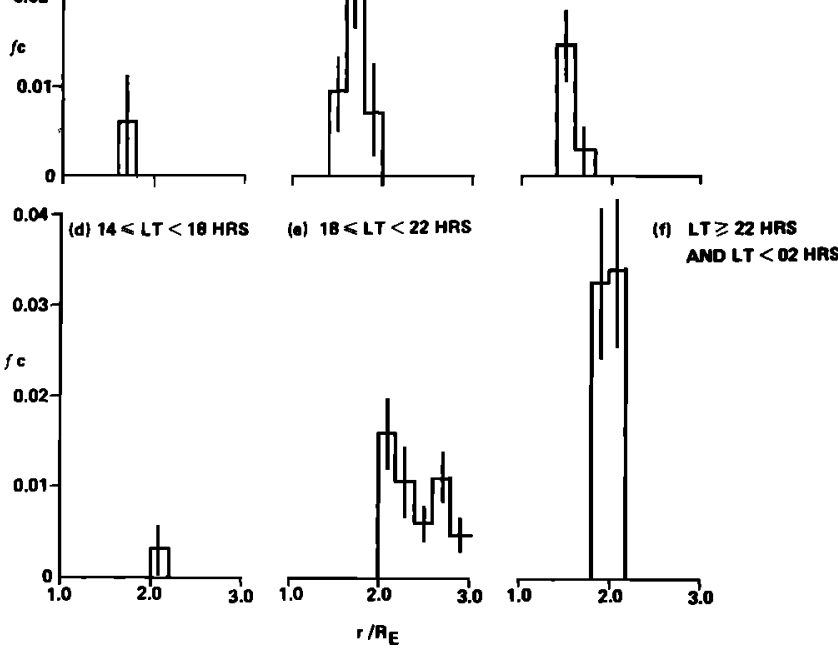

Fig. 2. Occurrence frequencies of transversely accelerated $\mathrm{O}^{+}$, $f_{c}$, in $\left(r / R_{E}\right)$ bins of width 0.2 for all $K p$ all days of year and $\Lambda \geqslant$ $50^{\circ}$ and local times (a) 0200-0600, (b) 0600-1000, (c) 1000-1400, (d) 1400-1800, (e) 1800-2200, and (f) 2200-0200. Error bars are plus and minus one standard deviation, and only values for in excess of 15 samples are shown.
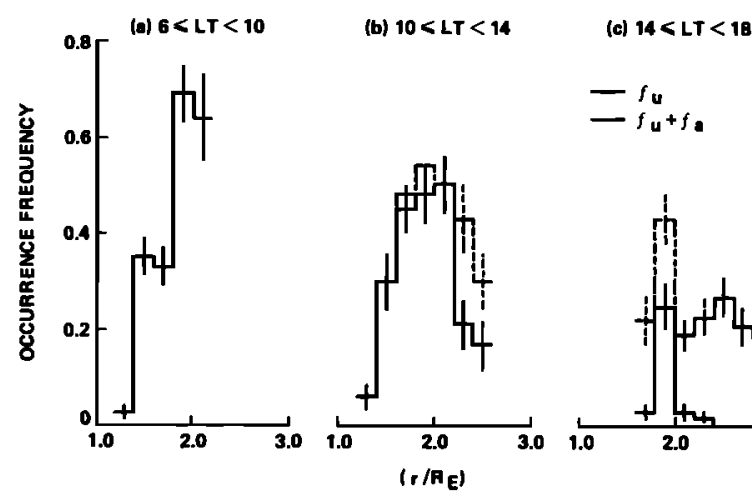

Fig. 3. Occurrence frequencies $f_{u}$ (solid lines) and $\left(f_{u}+f_{a}\right)$ (dashed lines) in $0.2-R_{E}$ altitude bins for the invariant latitude range $75^{\circ} \leqslant$ $\Lambda<80^{\circ}$, all $K p$ and all times of year, and three local time ranges, 0600-1000, 1000-1400, and 1400-1800. Error bars are plus and minus one standard deviation, and only values for in excess of 15 samples are shown.

In addition, if the source is sufficiently below the satellite, or if a parallel field-aligned potential drop exists, $\mathrm{O}^{+}$ conics may appear as a field-aligned flow where the count rate minimum at the field-aligned direction is too small to be resolved by the angular response of the radial head. However, Plate $4 b$ shows that the occurrence probability of field-aligned flows, $f_{a}$, is also low on the nightside. Conics which are only the hot tail of the distribution may have been masked by the cold rammed component, in the way that the conical ions at 1124-1126 UT on April 15, 1982 (Figure 1) were masked by the colder ions.

By contrast, the upwelling $\mathrm{O}^{+}$ions are observed exclusively in the morning sector of the auroral oval and the lower latitudes of the polar cap (the dark blue areas in Plate $4 a$ in fact correspond to $f_{u}=0$, not just $f_{u}<0.1$ ). Integrated over the whole altitude range below $3 R_{E}, f_{u}$ up to 0.6 are observed in this local time sector. The probability of field-aligned flow is small $\left(f_{a}<0.1\right)$ in this sector, but values up to 0.3 are found in the afternoon sector. The sum of $f_{a}$ and $f_{u}$ (Plate $4 d$ ) shows that upward field-aligned $\mathrm{O}^{+}$ flow (of either type of spin distribution) is a regular feature on the dayside, with peak probabilities at $\Lambda$ between $75^{\circ}$ and $80^{\circ}$

\subsection{Altitude Distributions}

The occurrence frequencies of $\mathrm{O}^{+}$TACI's, $f_{c}$, as a function of altitude, are shown in Figure 2 for $\left(r / R_{E}\right)$ bins 0.2 wide, for all samples poleward of $\Lambda=50^{\circ}$ and six local time ranges. For each local time bin, $f_{c}$ shows a peak between the lowest and greatest altitudes (where $f_{C}$ goes to zero, with the exception of $r / R_{E}=3.0$ for $1800 \leqslant \mathrm{LT}<2200$ ). If we assume that an $\mathrm{O}^{+}$ion, once transversely accelerated, is moved upward by a gradient- $B$ mirror force which exceeds gravitational binding, the fall in $f_{c}$ with $r$ for the range $2.0 \leqslant r / R_{E}<3.0$ must indicate that the TACI's either have been folded or scattered to cone angles smaller than the angular resolution of the radial head (about $15^{\circ}$ ) or have been further accelerated to an energy at which RIMS fails to detect then ( $\geqslant 60 \mathrm{eV})$. The lowest altitude at which $\mathrm{O}^{+}$TACI's are observed varies with local time over the range $r / R_{E}=1.4-2.0$; below this height any $\mathrm{O}^{+}$TACI's must be too narrow in latitudinal width, or too small a 


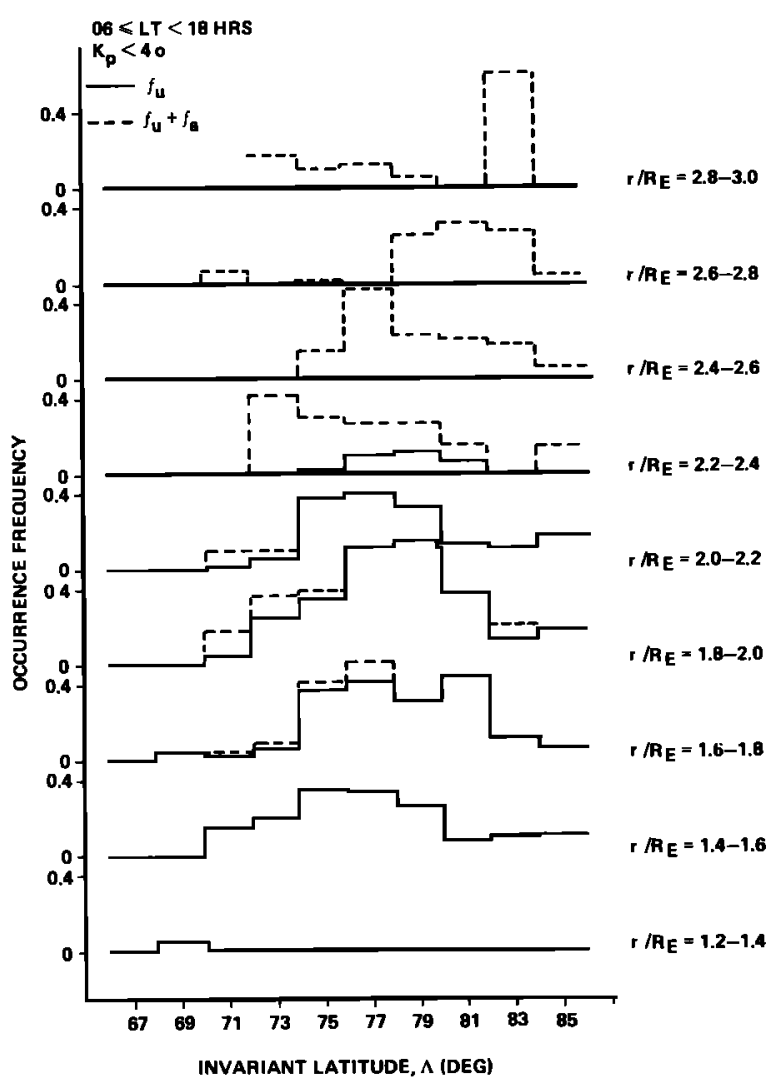

Fig. 4. Occurrence frequencies $f_{u}$ (solid line) and $\left(f_{u}+f_{a}\right)$ (dotted line) in bins of $2^{\circ}$ of invariant latitude and of 0.2 in $\left(r / R_{E}\right)$, for all samples when $K p<40$ and $0600 \leqslant \mathrm{LT}<1800$. Only values for in excess of 15 samples are shown. For clarity, standard deviations have not been plotted but are everywhere less than 0.1 and in most cases are less than 0.03 .

fraction of the total low-energy $\mathrm{O}^{+}$population to be detected in the 1-min integrations of the RIMS data used here.

The variation of the occurrence frequencies of upwelling and field-aligned flows with altitude is given in Figure 3. Bins of $\left(r / R_{E}\right)$ width of 0.2 and of local time width of 4 hours have again been used, but this time only for $75^{\circ} \leqslant$ $\Lambda<80^{\circ}$ (where $f_{u}$ and $\left(f_{u}+f_{a}\right)$ are maxima; see Plate 4). The solid curve shows $f_{u}$, and the dashed curve $\left(f_{u}+f_{a}\right)$. As for the $\mathrm{O}^{+}$TACI's, $f_{u}$ falls with decreasing $r$ at low $r$, but with increasing $r$ at high $r$. The former effect is due to the altitude distribution of detectable flows, but the latter decrease implies that as $r$ approaches $3 R_{E}$, they may be classified differently, possibly as field aligned. Figure 3 demonstrates this is the case for the 1400-1800 local time bin, but is only a partial explanation for 1000-1400. Additional factors could be secondary heating (to above $60 \mathrm{eV})$ or the convection of the flows to higher $\Lambda\left(>80^{\circ}\right)$ at greater altitudes (see Figures 4 and 5).

Upwelling ions are seen with $f_{u}>0.05$ at $\left(r / R_{E}\right)$ greater than 1.4 for $0600 \leqslant \mathrm{LT}<1000$ and $1000 \leqslant \mathrm{LT}<1400$ and 1.8 for $1400 \leqslant L T \leqslant 1800$. These statistical loweraltitude limits for upwelling ions are consistent with the source for the conical ions embedded within the event shown in Plate 3 and Figure 1, which was computed in subsection 3.3 to be near $\left(r / R_{E}\right)=1.5$. Note that the upwelling ions are a very persistent feature with occurrence prob- abilities near 0.7 for certain bins. In fact, such ions were detected at some point along virtually every pass of $D E 1$, which crossed the polar cap boundary region at an $r / R_{E}$ of $1.5-2.0$ in the $0600-1400$ LT sector, when RIMS was operating in a suitable mode.

The variation of $f_{u}$ and $\left(f_{u}+f_{a}\right)$ with $\Lambda$ for various altitude ranges is shown in Figures 4 and 5 . The location of the upwelling ion events is a function of $K p$ (see section 5 ), and hence these variations have been evaluated for $K p<40$ (Figure 4) and $K p \geqslant 40$ (Figure 5), two ranges which contain approximately equal numbers of samples for the $0600 \leqslant \mathrm{LT}<1800$ range used.

In Figure 4 a slight shift of the region of upwelling ions to higher $\Lambda$ can be seen with increasing altitude. Above $\left(r / R_{E}\right)=2.4, f_{u}$ goes to zero; however, the trend is continued by field-aligned flows. The same features can be identified in Figure 5 but with some differences: events extend down to lower latitudes, and the region of upwelling ions is broaded in $\Lambda$; more field-aligned flow events are observed which do not follow the trend to greater $\Lambda$. Figures 4 and 5 indicate that as the upwelling ions ascend in altitude, the spin distribution of the $\mathrm{O}^{+}$population detected by RIMS evolves to a more symmetric form and the upwelling ions become classified as field-aligned flows. This may not be due to an evolution in the spin distribution of the total $\mathrm{O}^{+}$population, but may be caused by the expected increase in spacecraft potential, $\phi_{S}$, with altitude (at low plasma densities, $\phi_{s}$ is positive, and RIMS may not

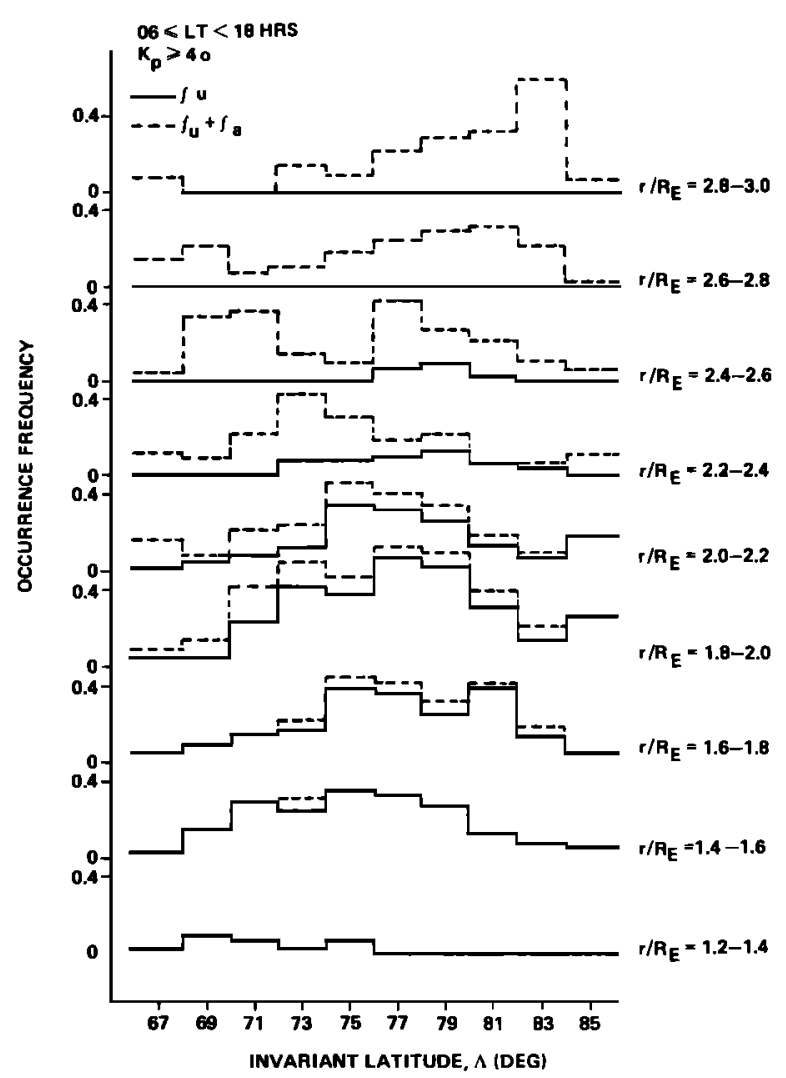

Fig. 5. Occurrence frequencies $f_{u}$ (solid line) and $\left(f_{u}+f_{a}\right.$ ) (dotted line) in bins of $2^{\circ}$ of invariant latitude of 0.2 in $\left(r / R_{E}\right)$, for all samples when $K p \geqslant 40$ and $0600 \leqslant L T<1800$. Only values for in excess of 15 samples are shown. For clarity, standard deviations have not been plotted but are everywhere less than 0.1 and in most cases are less than 0.04 . 

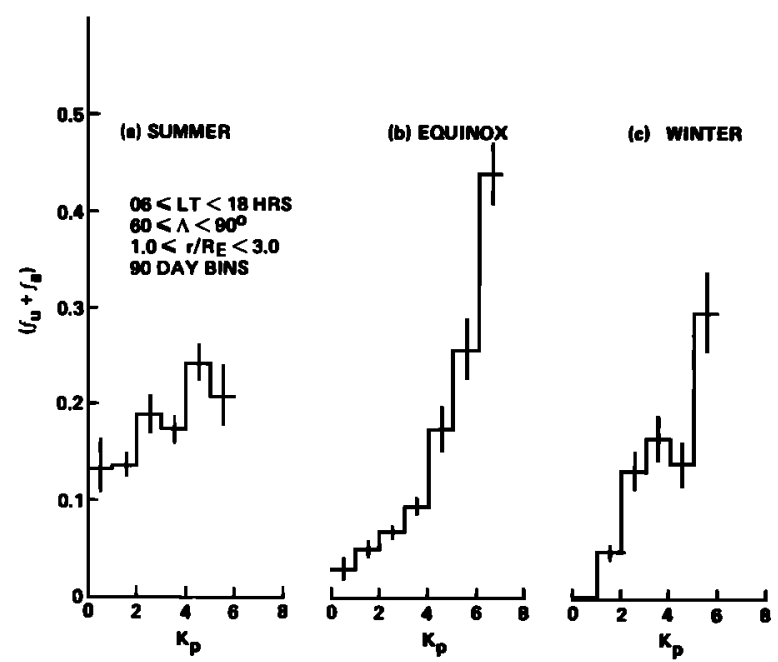

Fig. 6. Variations of $\left(f_{u}+f_{a}\right)$ with $K p$ for 90-day periods about (a) the summer solstice, (b) either equinox, and (c) the winter solstice, and for $\Lambda \geqslant 60^{\circ}, 0600 \leqslant \mathrm{LT}<1800$ and $\left(r / R_{E}\right)<3$. Error bars are plus and minus one standard deviation, and only means for in excess of 100 samples are shown.

be sampling the lowest-energy ions). Figure $1 b$ shows that if $\phi_{s}$ had been greater, then only the ions in RPA step numbers 750-1000 would have been detected, and the event would have been classified as a field-aligned flow region poleward of a conical ion region. At greater heights the conics would be folded to cone angles below the angular resolution of the radial head, and the whole event would be classified as field aligned.

The energies of a large part of the upwelling ions are sufficiently low for convection to carry them over a considerable distance away from the source region. Convection is expected to be antisunward over the entire polar cap if the interplanetary magnetic field (IMF) $B_{z}$ component is less than about $1 \mathrm{nT}$; in this case all upwelling ions would be swept to higher latitudes and toward the nightside. For strongly northward IMF $\left(B_{z}>1 \mathrm{nT}\right)$, antisunward convection is only expected around the low-latitude flanks of the cap, but some upwelling ions at higher latitudes will be moved to lower latitudes. Plate 4 shows that at $r<$ $3 R_{E}$, significant flows can regularly extend into the nightside of the $0600-1800$ meridian around the flanks of the cap, particularly on the dawnside.

\subsection{Seasonal and $K p$ Variations}

The problem with attempting to find seasonal variations in these data is that the highly elliptical orbit of DE 1 does not give an even distribution of samples with local time and altitude for any given season, as is demonstrated by Table 1. The low sample numbers for the equinoxes at greater altitudes on the dayside is overcome by combining spring and autumn data. In addition, to prevent an altitude bias in sample numbers affecting the results, only the probability $\left(f_{u}+f_{a}\right)$ is studied, given that Figures 4 and 5 and Figure 11 of Waite et al. [1985] show that on the dayside, field-aligned flow appears to be the high-altitude signature of the upwelling ion events in the RIMS data set. To prevent any further sampling bias effects, only bins of size which give in excess of 100 samples are considered. To achieve this, all latitudes above $\Lambda=60^{\circ}$ on the entire dayside $(0600 \leqslant \mathrm{LT}<1800)$ were employed. Figure 6 shows the $K p$ variation of $\left(f_{u}+f_{a}\right)$ for all such samples taken in 90 -day bins about the summer and winter solstices and either equinox. In all three cases the probability of observing upflowing $\mathrm{O}^{+}$ions on the dayside increases with $K p$. At very low $K p(<10),\left(f_{u}+f_{a}\right)$ is highest in summer, small at equinox, and zero in winter. However, for the highest $K p$ (for which sufficient samples are available in all three seasons; i.e., $50 \leqslant K p<6$ ) the seasonal variation is smaller, with $\left(f_{u}+f_{a}\right)$ highest in winter and lowest in summer.

\section{INVARIANT LATITUDE OF UPWELLING ION EVENTS AND ASSOCIATION WITH FIELD-ALIGNED CURRENTS}

Comparison of Figures 4 and 5 reveals a slight equatorward shift of the location of upflowing ion events at higher $K p$. This effect is confirmed by the scatter plots shown in Figure 7, which show the invariant latitudes of the upperlatitude $\left(\Lambda_{b}\right.$, open circles) and lower-latitude $\left(\Lambda_{a}\right.$, solid circles) edges of upwelling ion events as a function of $K p$ for local times ranges (Figure 7a) 0600-1000 and (Figure $7 b$ ) 1000-1400. Both upper and lower edges to the event move equatorward as $K p$ increases, in both local time ranges, by between $1.5^{\circ}$ and $2^{\circ}$ per unit $K p$. The latitudinal width of the event is generally greater in the sector about noon, and there is a slight increase in that width with $K p$. Note that although for the majority of events, $\Lambda_{a}$ is roughly consistent with the latitude of the polar cap boundary, a small number are at very high latitudes within the cap

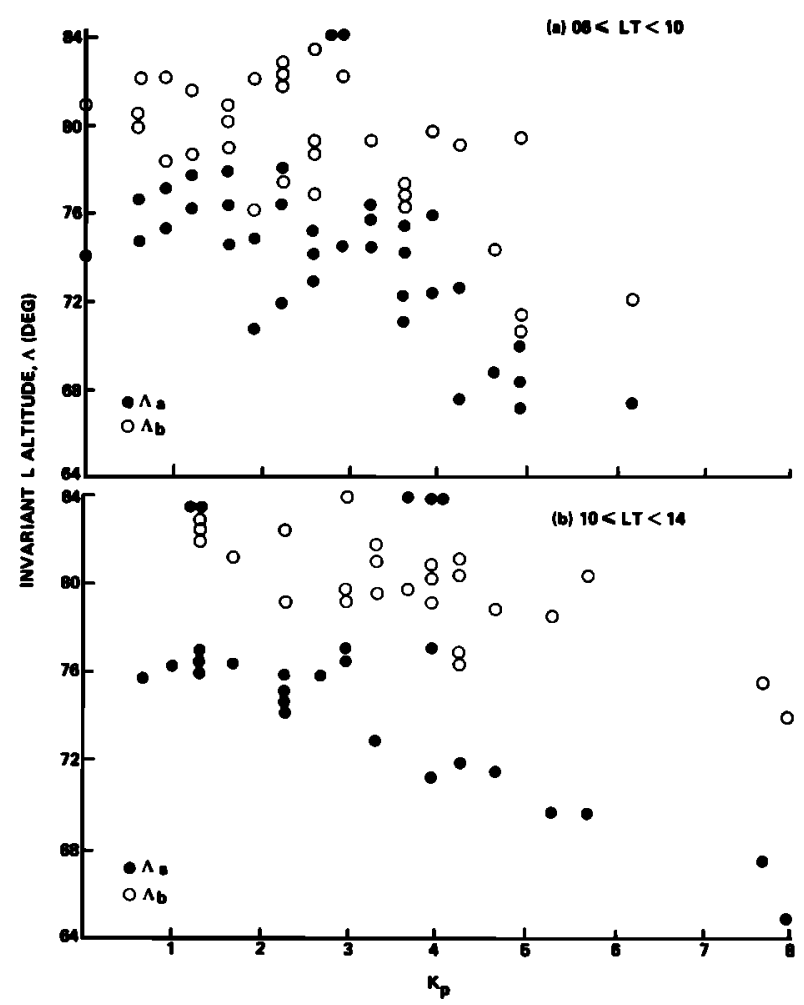

Fig. 7. Scatter plots of the invariant latitudes $\Lambda_{b}$ and $\Lambda_{a}$ of the high-latitude (open circles) and low-latitude (solid circles) edges of upwelling ion events as a function of $K p$ for local time ranges (a) $0600-1000$ and (b) $1000-1400$. 
(shown here at $\Lambda_{a}=84^{\circ}$; as $L>100$ for these events).

The lower-latitude edge of the upwelling ions is found to be closely associated with field-aligned currents, as observed by the magnetometer on board DE 1 [Farthing et al., 1981]. Figure 8 shows observations by the DE 1 magnetometer between 1110 and 1140 UT on April 15, 1982 , during which period the upwelling ion event shown in Plate 3 was observed by RIMS. The variation of the deviation of the observed eastward component from the Magsat model internal field, $\Delta \boldsymbol{B}_{\phi}$, is plotted and shows significant variation between about 1120 and 1126 UT, coincident with the upwelling ion event.

A total of 70 upwelling ion events are available, for which there are concurrent magnetometer data available from the DE 1 magnetometer. In all but three of the 70 available cases, some such signature in $\Delta B_{\phi}$, indicating fieldaligned currents, was observed in association with each upwelling ion event. For an infinite current sheet model an increasing $\Delta B_{\phi}$ with decreasing latitude indicates an upward field-aligned current region. In some of the 67 examples, apparently upward field-aligned currents were found poleward of an apparently downward current region, in others they were equatorward of the downward currents, and in a third type they were between two regions of downward current. It was noted that in most cases the lowlatitude edge of the region of apparently downward current (determined from $\Delta B_{\phi}$ ), at an invariant latitude of $\Lambda_{c}$, was encountered at almost exactly the same time as RIMS observed the lower-latitude edge of the upwelling ion event. This can be seen in Figure 9, which shows a scatter plot of $\Lambda_{c}$ against the latitude of the equatorward edge of the upwelling ions, $\Lambda_{a}$. The error bars in $\Lambda_{a}$ correspond to the change of the location of DE 1 in $\pm 30 \mathrm{~s}$ and are due to the use of $1-\mathrm{min}$ integrations of the RIMS data. The difference between $\Lambda_{c}$ and $\Lambda_{a}$ is always less than $2^{\circ}$ and is less than $1^{\circ}$ in $64 \%$ of the 70 cases. To within the known errors, $\Lambda_{c}$ equals $\Lambda_{a}$ in $70 \%$ of the cases $\left(\Lambda_{a}\right.$ is greater than $\Lambda_{c}$ by

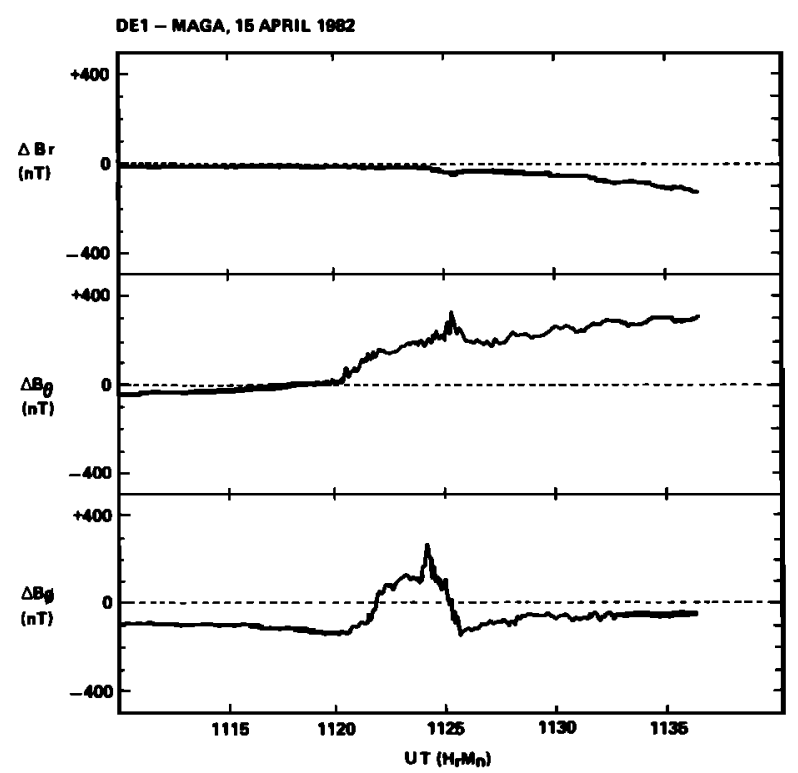

Fig. 8. Variations of deviations of the components of geomagnetic field from the Magsat model values, $\Delta B_{r}, \Delta B_{\theta}$, and $\Delta B_{\phi}$ from the DE 1 magnetometer between 1110 and 1140 UT on April 15, 1982 (see Plate 3 for concurrent RIMS data).

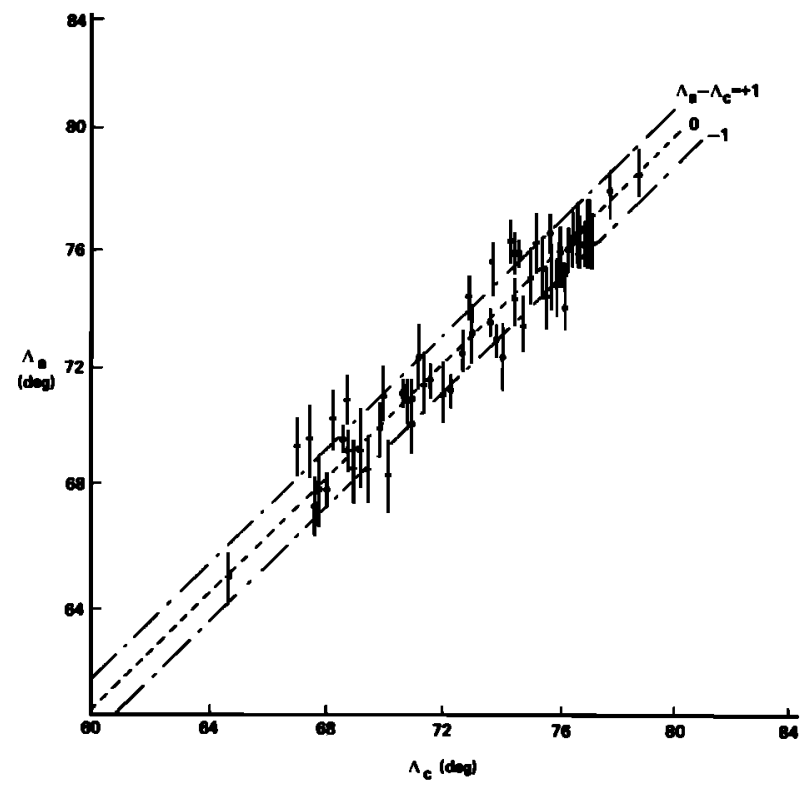

Fig. 9. Scatter plot of the invariant latitude of the equatorward edge of upwelling ion events, $\Lambda_{a}$ (with error bars due to the satellite motion during the 1-min integration period) as a function of the invariant latitude of the equatorward edge of the associated region of decreasing $\Delta B \phi, \Lambda_{c}$.

more than this uncertainty in $16 \%$ of cases, whereas $\Lambda_{c}>$ $\Lambda_{a}$ in $7 \%$ of cases; $4 \%$ show no field-aligned current, and $3 \%$ show such currents, but no clear $\Lambda_{c}$ can be determined). Upwelling ions are usually found to extend considerably poleward of the region of apparently downward current (although in a very few cases the converse is true). Interpretation of the magnetometer traces in terms of fieldaligned currents is complex and is most satisfactorily done on a case-by-case basis. Figure 9 demonstrates there is a connection between the lower-latitude edge of the upwelling ion events and field-aligned currents. If a simple current sheet model can be applied to these cases, it can be further stated that the association is usually with downward fieldaligned currents, although sometimes upwelling ions do extend equatorward into a region of upward current.

\section{DISCUSSION}

The ionosphere is known to be the source of the large abundances of $\mathrm{O}^{+}$ions found within the magnetosphere as the solar wind contains insufficient oxygen, of any charge state [Bame et al., 1970]-even if sufficient entry and charge exchange mechanisms are active [Prange, 1978; Johnson, 1979]. Subsequent to leaving the ionosphere, these ions reach nearly all regions of the magnetosphere and, along whatever paths they follow, they are accelerated to a wide range of final energies. In this section we shall discuss how the upwelling ion events described in this paper could act as a major source of $\mathrm{O}^{+}$ions for a variety of regions in the magnetosphere, due to the effects of the convective electric fields (subsection 6.1). An estimate of the total rate of $\mathrm{O}^{+}$ion outflow from the ionosphere, due to upwelling ions, is given in subsection 6.2 , and the results are compared to previous observations of lowaltitude $\mathrm{O}^{+}$flow at high latitudes in subsection 6.3 . 


\subsection{The Effect of Convective Electric Fields}

The effect of large-scale convective fields on an upward flow of $\mathrm{O}^{+}$ions is very dependent on the velocity with which they leave the topside ionosphere: if the ions have only the minimum energy required to escape gravitational binding (a few electron volts), they will be convected over considerable distances before they reach greater altitudes, and the ionospheric source will lie "upstream" along the convection trajectory (the equipotential) [Waite et al., 1985 ] ; however, if the ions have higher energies, they will be less affected by the electric fields. The results presented in this paper show that the dayside polar cap boundary region is a persistent and strong source of very lowenergy $\mathrm{O}^{+}$ions $(\leqslant 10 \mathrm{eV})$, which could be convected over the entire cap toward the nightside when the IMF is southward $\left(B_{z}<1 \mathrm{nT}\right)$ or only round the flanks of the cap when the IMF is strongly northward $\left(B_{z}>1 \mathrm{nT}\right)$. Even for the low altitudes studied here $\left(<3 R_{E}\right)$ the data have the following features which are consistent with a convection velocity filter effect and dispersion of ions in both mass and energy: (1) decreasing energy of $\mathrm{O}^{+}$with increasing latitude; (2) occurrence frequency distributions for $\mathrm{O}^{+}$which peak at greater latitudes (and have greater width) at greater altitudes; (3) an increase in latitudinal width of upwelling ion events with $K p$; and (4) light ions upwelling at slightly lower latitudes than $\mathrm{O}^{+}$. Higher-altitude data from RIMS also show this "geomagnetic mass spectrometer" effect, with lighter ions found closer to the dayside cap boundary and decreasing energy of ions of any species observed as DE 1 moves antisunward across the polar cap [Waite et al., $1985 ;$ Moore et al., 1985]. The idea of such an effect was first put forward in relation to the dispersion of incoming cusp ions by Rosenbauer et al. [1975], Shelley et al. [1976], Reiff et al. [1977], and Burch et al. [1982]. The RIMS observations show that both mass and energy dispersions also occur for upflowing ionospheric ions.

Observations at higher altitudes by the HAPI instrument on DE 1 have previously revealed energy dispersion of upgoing ionospheric ions poleward of the cusp [Gurgiolo and Burch, 1982, Figure 1a]; however, the authors described these ions as coming from the cusp and cap, not a localized source near the dayside auroral zone, as is found by these lower-altitude data from RIMS. The energy dispersion effect is seen by DE RIMS with such clarity because the narrow ionospheric source region at the dayside polar cap boundary acts as a "slit" for the geomagnetic mass spectrometer. Comparison of the energy spectra observed by the $Z$ heads, during upwelling ion events, shows that upwelling $\mathrm{H}^{+}$and $\mathrm{He}^{+}$ions have similar ranges of energies to the $\mathrm{O}^{+}$ions (zero to about $30 \mathrm{eV}$ ). No information on the light ion energies is available from the radial head, so it is not known if the spectra for the field-aligned components of upwelling ions of different species are also similar. Ions of the same energy will show mass dispersion as they are separated according to their field-aligned velocities. Figure 5 of Moore et al. [1985] shows that in a poleward pass over the dayside polar cap, RIMS observed firstly field-aligned flows of $\mathrm{H}^{+}$ions, then $\mathrm{He}^{+}$, and lastly $\mathrm{O}^{+}$, indicating that the ions had left a dayside source with similar energies for the different species. Note that Moore et al. observed all these ions at high altitudes without the use of a negative bias on the RIMS aperture ring; hence, the light ions are not classical polar wind ions, which are of lower energy, and negative bias is required to offset the positive spacecraft potential and allow their observation [Nagai et al., 1984]. The features are represented schematically in Figure 10 for solstice conditions. The results in subsection 4.3 show that at very low $K p$, upwelling ions are only found in the summer hemisphere. Under such conditions, convection is likely to be weak, and the ion flows are not shifted as far from the dayside polar cap boundary as they are under strong convection conditions; hence, the upwelling ions are a source of very low-energy plasma for the mantle, lobes, and plasma sheet regions of the geomagnetic tail (Figure 10a). Figure $10 b$ shows the expected situation at high $K p$ and with rapid antisunward convection. In this case both hemispheres yield upwelling ions and, if convection is strong enough, $\mathrm{O}^{+}$could be convected right over the cap into the nightside where it could feed into the nightside auroral acceleration regions (at $r$ greater than about $2 R_{E}$ [Ghielmetti et $\left.a h, 1978\right]$ ) and hence act as a source of $\mathrm{O}^{+}$beams and conics [Collin et al., 1984]. This mechanism could therefore be one possible explanation of the observed variability of the occurrence of $\mathrm{O}^{+}$beams and conics with energies greater than $0.5 \mathrm{keV}$ on nightside auroral field lines [Kintner et al., 1979]. The flows of $\mathrm{O}^{+}$ions from upwelling ion events will extend to lower latitudes on the nightside than the "tongue" of cold, isotropic $F$ region plasma caused by antisunward convection [Knudsen, 1974 ]; this is because the $F$ region $\mathrm{O}^{+}$is subject to loss processes which the high-altitude $\mathrm{O}^{+}$flows are not subject to. During periods of strong convection the tongue has been modeled to extend right over the cap to the nightside oval [Sojka et al., 1981], and enhanced densities have been observed just poleward of the nightside auroral oval by Lockwood et al. [1984]. At times when unheated $F$ region plasma can reach the nightside oval, slightly heated $\mathrm{O}^{+}$ will reach nightside auroral field lines at low altitudes. Waite et al. [1985] observed $\mathrm{O}^{+}$flows which extended throughout the cap at $2-4 R_{E}$, and in some cases right into the nightside auroral oval.

As well as showing how the dayside ionosphere could act as a source of the energetic $\mathrm{O}^{+}$beams and conics on the nightside, the convection effect illustrated in Figure 10 sets limitations as to which parts of the nightside auroral ionosphere could be an alternative source for these ions. The implications depend upon the shape of the convection pattern. Heelis and Hanson [1980] have shown from AE-C data that the polar cap boundary is an equipotential near dawn and dusk (that shear flow reversals occur there) and that such regions extend round into the nightside by varying amounts. Where the cap boundary is not an equipotential on the nightside, convection has a large equatorward component as plasma leaves the polar cap. Any $\mathrm{O}^{+}$leaving the ionosphere at these local times with the minimum energy needed to reach a geocentric distance of $2 R_{E}$ will convect off auroral field lines and then sunward on subauroral field lines: such ions will not be fed into the nightside oval at $2 R_{E}$. Hence where the cap boundary is not an equipotential (which can be most of the night sector), the auroral ionsophere can only feed higher-energy $\mathrm{O}^{+}$(which does not convect as far) into the beam and conic generation regions. Where the cap boundary is an equipotential, the low-energy $\mathrm{O}^{+}$will convect sunward but can also 


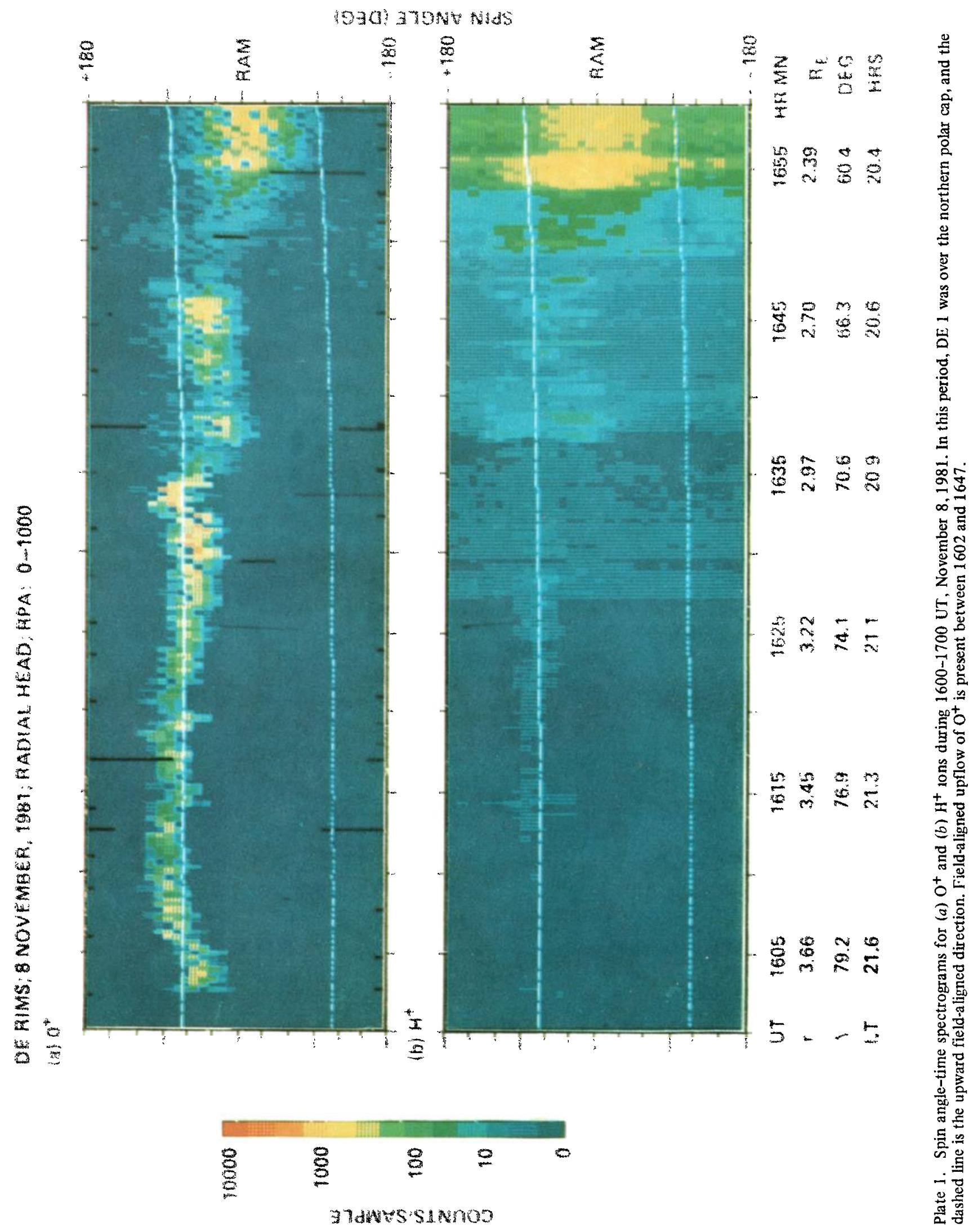




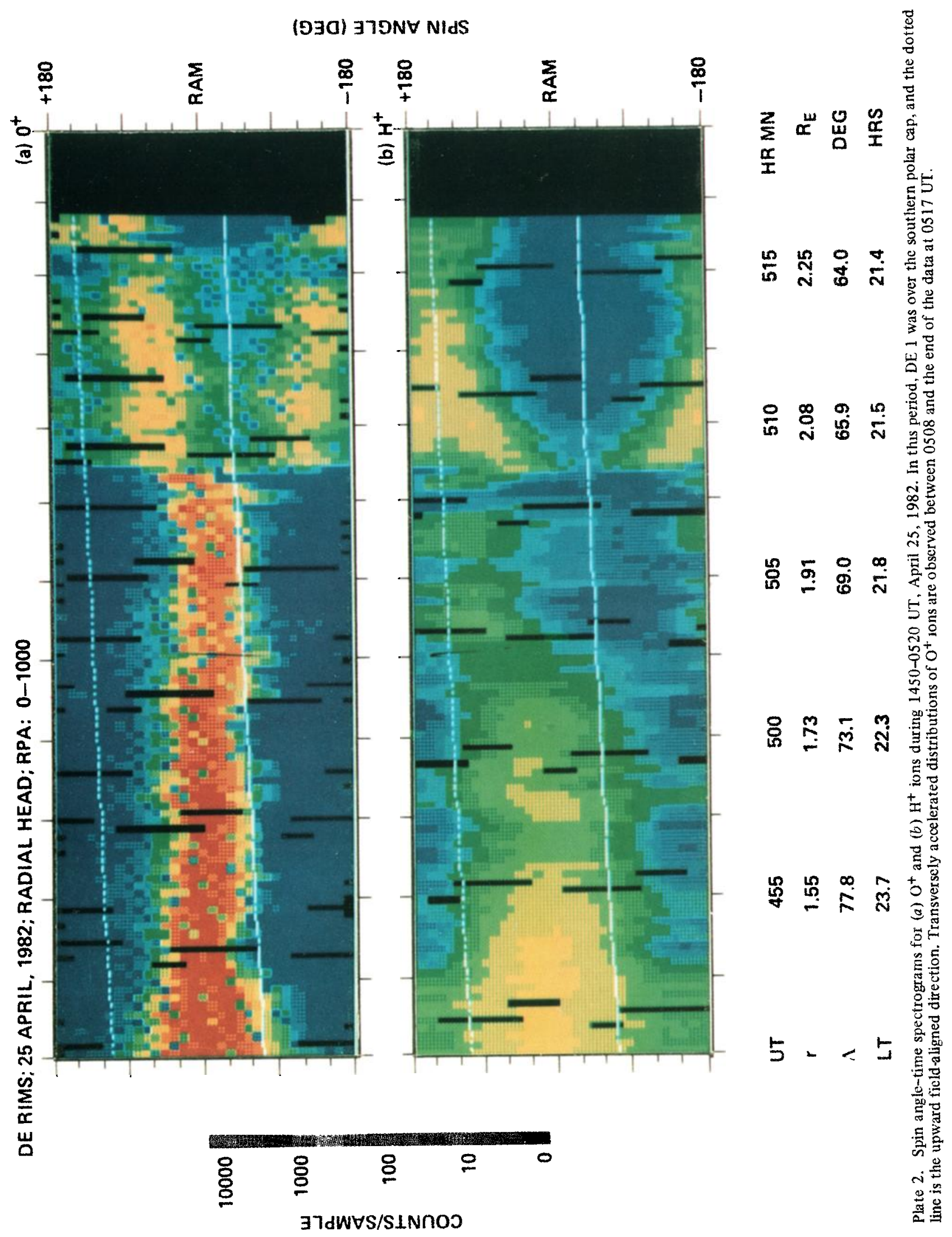


DE HIMS: TS ARRL. 1982

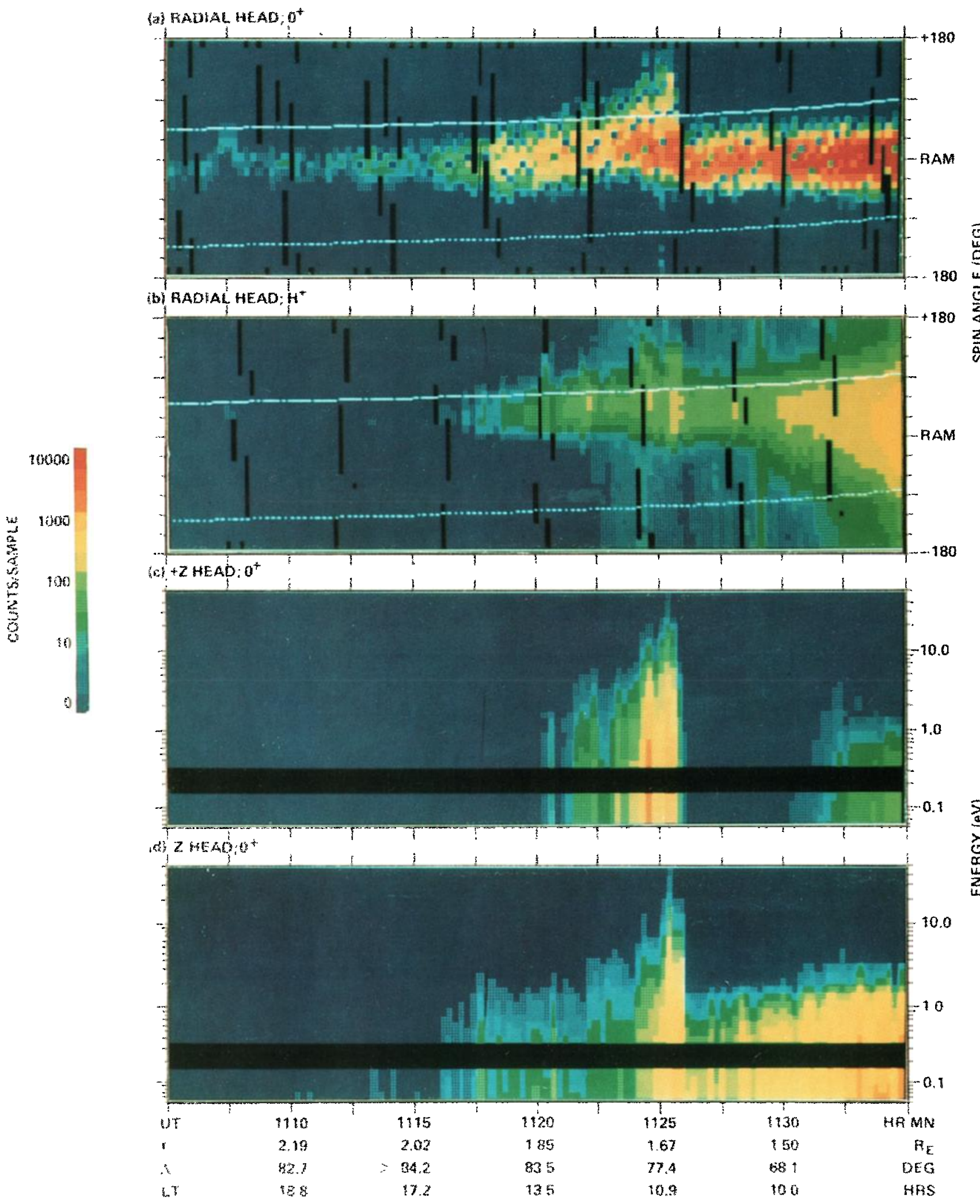

Plate 3. Spin angle-time spectrograms for $(a) \mathrm{O}^{+}$and $(b) \mathrm{H}^{+}$ions and energy-time spectrograms from the $(c)+Z$ and (d) $-\%$ heads during 1105-1135 UT, April 15, 1982. In this period, DL 1 was over the northern polar cap, and the dashed line is the upward field-aligned direction. Asymmetric spin distributions are observed in $\mathrm{O}^{+}$between 1120 and $1126 \mathrm{UT}$. and warm $(>2 \mathrm{eV}) \mathrm{O}^{+}$ions are observed by both 7 . heads between 1124 and $1126 \mathrm{UT}$. 

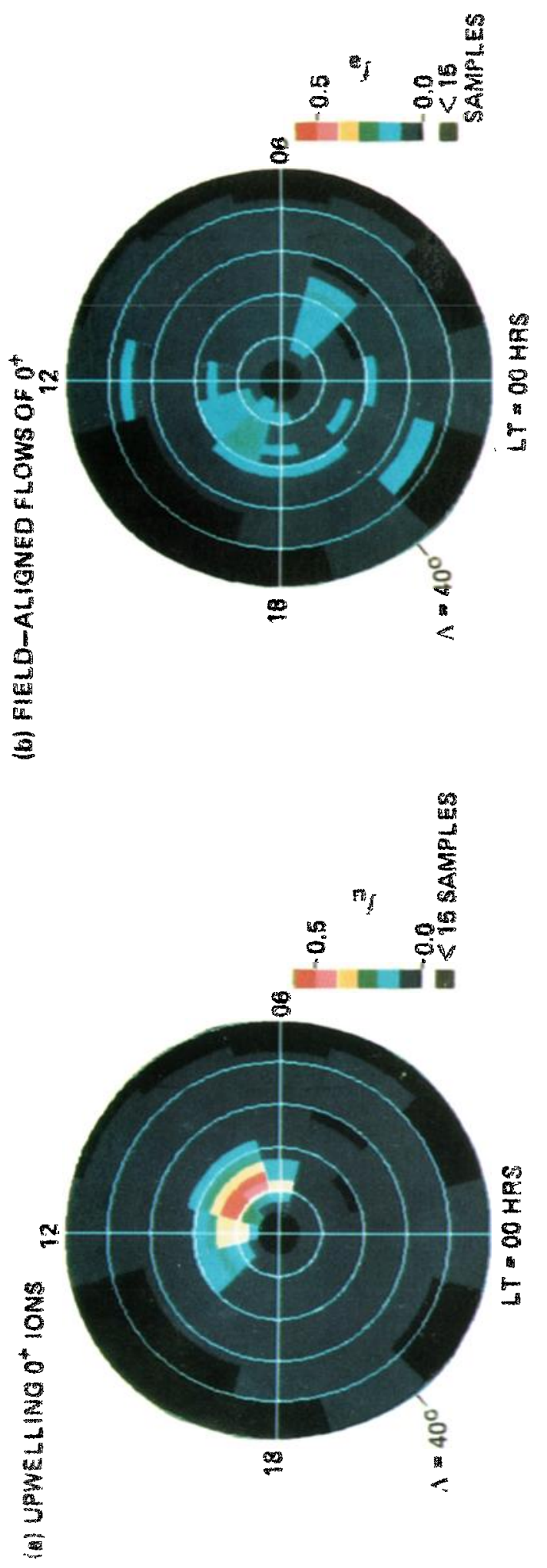

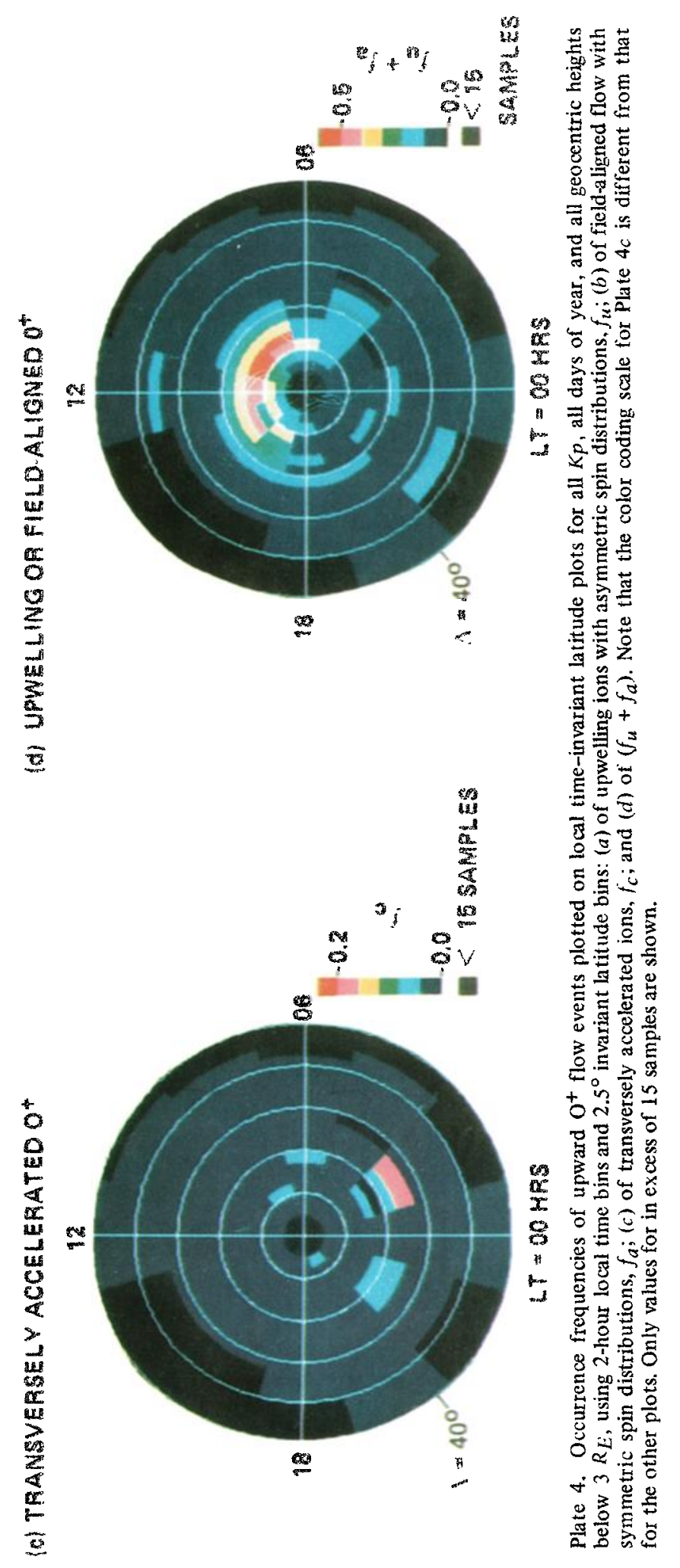


(a) LOW KP, WEAK ANTISUNWARD CONVECTION

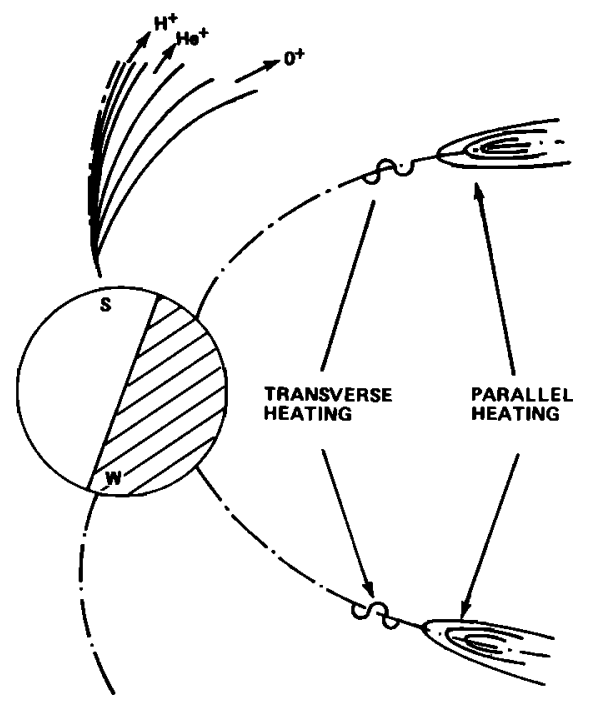

(b) HIGH Kp, STRONG ANTISUNWAAD CONVECTION

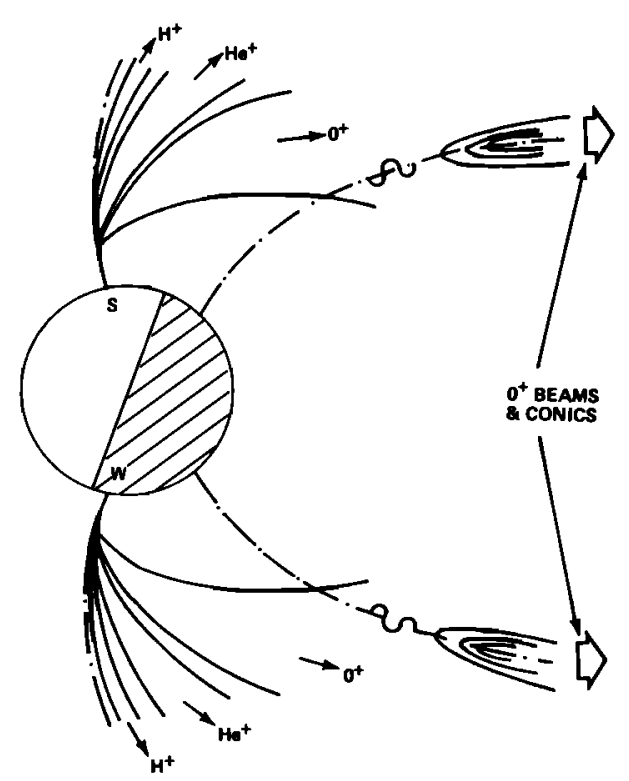

Fig. 10. Schematic representation of the newly observed dayside source of low-energy ions showing how it can act as a source of heavy ions (in particular $\mathrm{O}^{+}$) for the polar cap and, under the correct conditions, for the nightside auroral acceleration regions. The limits to regions of large ion flow for the upwelling, heated ions of the major species are shown here by the solid lines, and the dashed lines denote auroral field lines. Solstice conditions are represented, with $S$ denoting the dayside auroral oval in the summer hemisphere and $W$ that in the winter hemisphere.

remain on auroral field lines. Such ions would only reach $2 R_{E}$ near dawn and dusk and hence could act as a source of beams and conics in these sectors. In general we can conclude that for the nightside to supply $\mathrm{O}^{+}$ions for the beams and conics near midnight, acceleration to considerable energies is required at low altitudes to minimize the convective drift. Such acceleration would overcome the gravitational binding and any charge exchange barrier [Moore, 1980; Lockwood, 1982] and may cause the ions to be undetected by RIMS (if the energy exceeds about $60 \mathrm{eV}$ ). Hence the velocity filter effect can also explain the absence of any major and persistent $\mathrm{O}^{+}$flows at $r<$ $3 R_{E}$ in the nightside oval at energies below $60 \mathrm{eV}$, as is observed by RIMS. Conversely, the dayside auroral ionosphere can supply the nightside oval above $2 R_{E}$, if the dawn-dusk electric field is large enough and the ions leave the ionosphere with sufficiently low velocities that they are convected over the polar cap.

\subsection{Estimate of $\mathrm{O}^{+}$Ion Flux and Total Outflow}

Coninputation of the fluxes of $\mathrm{O}^{+}$ions, cantied by all three classifications of $\mathrm{O}^{+}$flow, is made difficult by the requirements to know the spacecraft potential and the component of the ion convection velocity lying in the plane of the satellite orbit. A detailed study of these fluxes is now being undertaken; however, an initial estimate of the mean upflow in upwelling ion events is $10^{8} \mathrm{O}^{+}$ions $\mathrm{cm}^{-2}$ $\mathrm{s}^{-1}$ at $r=2.5 R_{E}$ : this is a conservative estimate; the true figure may be up to an order of magnitude larger. Normalized to an altitude of $1000 \mathrm{~km}$, this is a flux of $10^{9}$ $\mathrm{cm}^{-2} \mathrm{~s}^{-1}$ out of the ionosphere.

To emphasize the significance of the new upwelling ion events as a source of magnetospheric $\mathrm{O}^{+}$ions, an estimate of the total $\mathrm{O}^{+}$flow has been made. Using the above flux value to apply to all events, the occurrence probabilities given in Plate $4 a$ yield a minimum for the average total outflow of about $10^{25} \mathrm{O}^{+}$ions s-1 from both hemispheres. This is of the same order of magnitude as the $\mathrm{O}^{+}$outflow in upward flowing ion (UFI) events estimated by Collin et al. [1984]. The similarity of these values does not necessarily, however, argue for the dayside upwelling ions as an adequate source for the nightside acceleration regions. This is because, as illustrated in Figure 10 , not all $\mathrm{O}^{+}$ions will fall into such a region; however, if the energy of upwelling $\mathrm{O}^{+}$is low (and in the case presented here the vast majority of the $\mathrm{O}^{+}$is at energies below the approximately $2-$ to $30-\mathrm{eV}$ conical ions), then only a very small fraction may have sufficient energy to escape further acceleration and enter the plasma sheet or even lobes and mantle as cold plasma. In addition it should be stressed that both these total $\mathrm{O}^{+}$outflow estimates are crude. However, the total outflow in upwelling ion events is also of the same order of magnitude as that of the $\mathrm{O}^{+}$flows in the nightside polar cap seen at greater altitudes hy RIMS, as calculated by Waite et al. [1985].

\subsection{Comparison With Other Observations}

The presence of a dayside $\mathrm{O}^{+}$source is expected from the results of Waite et al. [1985], who found 2- to 8-eV $\mathrm{O}^{+}$ions in the nightside polar cap which, using electric field estimates from DE 2, mapped down to an ionospheric source near the dayside polar cap boundary. Waite et al. found such flows only when $K p$ was high, which is consistent with the results presented here, as their study was restricted to the winter polar cap. The persistence of the upwelling ion events argues for a quasi-steady state 
outflow, in which case large upflows (of order $10^{9} \mathrm{~cm}^{-2}$ $\mathrm{s}^{-1}$ or greater) should be observed below the upwelling ion events. Such flows have been observed near $6000 \mathrm{~km}$ by Lockwood [1982] and Farmer et al. [1984] and near $900 \mathrm{~km}$ by Heelis et al. [1984]. Figure 3 shows that upwelling ions are only very rarely seen by RIMS at $r$ below $1.4 R_{E}$. Large fluxes of $\mathrm{O}^{+}$at these altitudes may have remained undetected in this study since the high plasma densities expected at lower altitudes would give a large ion flux, even for field-aligned velocities which are small in comparison to the RAM velocity. For the case studied in this paper the most energetic ions are roughly $30-\mathrm{eV}$ conical ions which appear to have been transversely accelerated near $r=1.4 R_{E}$, below which upwelling ion events are found to be rare. This is also roughly the location of the ionospheric baropause, and the kinetic treatment of subsequent upward motion, used in subsection 3.3 to compute the source height, is probably valid. A study of ion fluxes from RIMS data in the dayside source region at $r<1.4 R_{E}$ is presently being carried out.

The increase in a dayside $\mathrm{O}^{+}$source with magnetic activity is consistent with topside ion flux observations by the European Incoherent Scatter (EISCAT) radar [Farmer et al., 1984] and topside soundings (M. Lockwood, unpublished manuscript, 1984) and with high-altitude RIMS observations [Waite et al., 1985].

Lockwood [1982] found the dayside auroral, topside ionosphere to regularly show the effects of upward flows of the magnitude required by upwelling ion flows assuming steady state (of flux greater than $10^{9} \mathrm{~cm}^{-2} \mathrm{~s}^{-1}$ ). In summer the occurrence frequency of such flows was near 0.3 for $70^{\circ} \leqslant \Lambda<80^{\circ}$. At low $K p(<20)$ such flows were mainly found in the morning sector (occurrence frequency near 0.5 for $70^{\circ} \leqslant \Lambda<80^{\circ}$ ), and the nightside oval contained such flow regularly at higher $K p$. These thermal ion flows could feed $\mathrm{O}^{+}$ions into all three types of $\mathrm{O}^{+}$ flow events described in this paper.

Heelis et al. [1984] have reported two examples of upward fluxes of thermal $\mathrm{O}^{+}$ions, observed by the ion drift meter (IDM) on DE 2 to exceed $6 \times 10^{10} \mathrm{~cm}^{-2} \mathrm{~s}^{-1}$ near $900 \mathrm{~km}$. Both examples were in regions of upward fieldaligned current, one in the premidnight, the other in the prenoon sector, and the ions were found to carry a large part of the total field-aligned current. The results presented here show that these two flow events seen by DE 2 will probably have resulted in higher-altitude $\mathrm{O}^{+}$flows which are of very different character: on the dayside an upwelling ion event is expected, whereas on the nightside a conical distribution is more likely. The seasonal variation of upwelling ions suggests some form of thermospheric or ionospheric control of the outflow and that the initial heating region may be below $3000 \mathrm{~km}$. The large upflows, observed by DE 2 in the morning sector, show a relation to regions of large velocity difference between ions and neutrals (R. A. Heelis, private communication, 1985), implying that Joule heating could be the heat source and it is possible that the upwelling ion signature is only observed by RIMS when the flows are no longer collision dominated.

As well as being consistent with the observations from the DE 1 RIMS experiment, as reported by Waite et al. [1985], the low-altitude $\left(<3 R_{E}\right)$ observations of upwelling ions and subsequent geomagnetic mass spectrometer effect are consistent with EICS [Shelley et al., 1982] and HAPI [Gurgiolo and Burch, 1982] observations from DE 1 when it was near its apogee of $4.6 R_{E}$. Shelley et al. [1982] found $\mathrm{O}^{+}$flows throughout the cap with an occurrence probability near 0.5 , consistent with the upwelling ion source and the effect of antisunward convection. Gurgiolo and Burch found upflowing ions of ionospheric origin in the dayside polar cap. The distribution function for these ions (Figure $4 d$ of their paper) is similar to what one would expect to see above an upwelling ion event if the vast majority of the upwelling ions (i.e., low-energy component) are cut out by spacecraft potential $(5-10 \mathrm{~V}$ for these observations near $4.5 R_{E}$ ) and by the $5-\mathrm{eV}$ threshold of the HAPI experiment. The lack of mass resolution makes it unclear as to which ion species were observed by Gurgiolo and Burch, but the ramp to lower energies at higher latitudes is consistent with the upwelling ions.

The low occurrence frequencies of nightside $\mathrm{O}^{+} \mathrm{TACI}$, as seen by RIMS, suggest that such ions are not generally as significant a source of $\mathrm{O}^{+}$for the magnetosphere as the dayside upwelling ions. This would be true at all but certain limited times when large numbers of $\mathrm{O}^{+}$are transversely accelerated over a wide range of latitudes. However, caution must be used in interpreting their near absence from this data set: conics and transversely accelerated ion events may have been overlooked if they are narrow in spatial extent, are energetic $(\geqslant 60 \mathrm{eV})$, or only carry a smaller flux of ions than the TACI's. It is valid to state that if large numbers of $\mathrm{O}^{+}$ions regularly leave the nightside oval, then they do so at energies above the $60-\mathrm{eV}$ detection limit of RIMS. The higher occurrence of thermal $\mathrm{O}^{+}$flow reported by Lockwood [1982] for low altitudes suggests that this may indeed occur at higher $K p$ values. Low-altitude, low-energy conics were observed close to source by the ISIS satellites. ISIS 2 found such ions at $1400 \mathrm{~km}$ in events of limited latitudinal width [Klumpar, 1979, 1981]. There was, however, no mass resolution in these observations, and hence it remains possible that even at this altitude the transversely accelerated ions were minority $\mathrm{H}^{+}$ions and not $\mathrm{O}^{+}$. In summer, transversely accelerated ions were only found by ISIS 1 at greater altitudes on the dayside, consistent with the upwelling ion source. Lockwood [1984] has analyzed the crude expectations of a nightside auroral source, via low-altitude transverse acceleration by ion cyclotron waves, and found it to be inconsistent with the observed solar cycle variation of ring current $\mathrm{O}^{+}$ abundance, suggesting it is not the sole source of such ions.

The low-latitude halves of upwelling ion events mainly occur in regions of apparently downward field-aligned current, which will be primarily carried by upgoing ionospheric electrons. Such a drift could excite the ion cyclotron instability and produce the "hot" tail of conical ions observed in these parts of the events (see references given by Lockwood [1984]). Note in some 7\% of cases, upwelling ions are also found in regions of apparently upward field-aligned current. In the one such case which we have studied, the ions have been found to make up the majority of the observed field-aligned current density, if the ionospheric electrons do not also flow upward. Such a drift of ions relative to cold ionospheric electrons would again be unstable to ion cyclotron waves. 


\section{CONCLUSIONS}

A new source of $\mathrm{O}^{+}$ions for the magnetosphere has been identified by the DE RIMS at low altitudes near the dayside polar cap boundary. All ion species are seen to move upward and to carry an upward heat flow, indicating that these ions are upwelling from a heated region beneath the satellite. The occurrence probability of observing such flows is much greater than those of the other upward $\mathrm{O}^{+}$ flows seen by the DE RIMS, namely nightside, low-altitude transversely accelerated core ions and field-aligned flows. Most of these ions are heated over ionospheric temperatures by a factor not much greater than that required to give gravitational escape: the highest-energy ions displaying conical pitch angle distributions and having energies of up to about $30 \mathrm{eV}$. The observations show a latitudinally narrow dayside heating region associated with a fieldaligned current (apparently downward) and a subsequent velocity filter effect, carrying the low-energy ions across the polar cap to the nightside. This mass spectrometer effect is consistent with higher-altitude observations made by RIMS and reported elsewhere. The occurrence of such flows increases with $K p$ and shows a seasonal variation: they are always present in summer but only at high $K p$ in winter. The flux of ions out of the ionosphere is of order $10^{9} \mathrm{~cm}^{-2} \mathrm{~s}^{-1}$, and the total $\mathrm{O}^{+}$ion outflow from this source is large (the average is at least $10^{25} \mathrm{~s}^{-1}$ for the 2 years in the falling phase of the solar cycle which are studied here).

Acknowledgments. The authors are grateful to the RIMS team at Marshall Space Flight Center (MSFC) and the programming staff of Intergraph and the Boeing Corporation for assistance with the data reduction software. Significant data analysis contributions were also made by Barbara Giles, an MSFC Co-op. We would also like to thank M. Sugiura for supplying the magnetometer data. Support for M. Lockwood came from the National Research Council, under their Resident Research Associateship program.

The Editor thanks J. Burch and D. M. Klumpar for their assistance in evaluating this paper.

\section{REFERENCES}

Axford, W. I., The polar wind and the terrestrial helium budget, J. Geophys. Res., 73, 6855, 1968.

Balsiger, H., P. Eberhardt, J. Geiss, and D. T. Young, Magnetic storm injection of $0.9-16 \mathrm{keV} / e$ solar and terrestrial ions into the high-altitude magnetosphere, J. Geophys. Res., 85, 1645, 1980.

Bame, S. J., J. R. Asbridge, A. J. Hundhausen, and M. D. Montgomery, Solar wind ions: $58 \mathrm{Fe}^{8+}$ to $56 \mathrm{Fe}^{12+}, 28 \mathrm{Si}^{7+},{ }^{28} \mathrm{Si}^{8+}$, $28 \mathrm{Si}^{9+}$, and $16 \mathrm{O}^{6+}, J$. Geophys. Res., 75, 6360, 1970.

Banks, P. M., and T. E. Holzer, High-latitude plasma transport: The polar wind, J. Geophys. Res., 74, 6317, 1969.

Barakat, A. R., and R. W. Schunk, $\mathrm{O}^{+}$ions in the polar wind, $J$. Geophys. Res., 88, 7887, 1983.

Barakat, A. R., and R. W. Schunk, $\mathrm{O}^{+}$charge exchange in the polar wind, J. Geophys. Res., 89, 9835, 1984.

Burch, J. L., P. H. Reiff, R. A. Heelis, J. D. Winningham, W. B. Hanson, C. Gurgiolo, J. D. Menietti, R. A. Hoffman, and J. N. Barfield, Plasma injection and transport in the mid-altitude polar cusp, Geophys. Res. Lett., 9, 921, 1982.

Candidi, M., S. Orsini, and V. Formisano, The properties of ionospheric $\mathrm{O}^{+}$ions as observed in the magnetotail boundary layer and northern plasma lobe, J. Geophys. Res., 87, 9097, 1982.

Chappell, C. R., Initial observations of thermal plasma composition and energetics from Dynamics Explorer 1, Geophys. Res. Lett., 9, 929, 1982.

Chappell, C. R., S. A. Fields, C. R. Baugher, J. H. Hoffman, W. B. Hanson, W. W. Wright, and H. D. Hammack, The retarding ion mass spectrometer on Dynamics Explorer-A, Space Sci. Instrum., $5,477,1981$.
Collin, H. L., R. D. Sharp, E. G. Shelley, and R. G. Johnson, Some general characteristics of upflowing ion beams over the auroral zone and their relationship to auroral electrons, J. Geophys. Res., 86, 6820, 1981.

Collin, H. L., R. D. Sharp, and E. G. Shelley, The magnitude and composition of the outflow of energetic ions from the ionosphere, J. Geophys. Res., 89, 2185, 1984.

Farmer, A. D., M. Lockwood, R. B. Horne, B. J. I. Bromage, and K. S. C. Freeman, Field-perpendicular and field-aligned plasma flows observed by EISCAT during a period of prolonged northward IMF, J. Atmos. Terr. Phys., 46, 473, 1984.

Farthing, W. H., M. Sugiura, and B. G. Ledley, Magnetic field observations on DE-A and -B, Space Sci. Instrum., 5, 551, 1981.

Frank, L. A., K. L. Ackerson, and D. N. Yeager, Observations of atomic oxygen $\left(\mathrm{O}^{+}\right)$in the earth's magnetotail, J. Geophys. Res., 82, 129, 1977

Geiss, J., H. Balsiger, P. Eberhardt, H. P. Wakker, L. Weber, D. T. Young, and $H$. Rosenbauer, Dynamics of magnetospheric ion composition as observed by the GEOS mass spectrometer, Space Sci. Rev., 22, 537, 1978.

Ghielmetti, A. G., R. G. Johnson, R. D. Sharp, and E. G. Shelley, The latitudinal, diurnal, and altitudinal distributions of upward flowing energetic ions of ionospheric origin, Geophys. Res. Lett., 5, 59, 1978.

Gorney, D. J., A. Clarke, D. Croley, J. Fennell, J. Luhmann, and P. Mizera, The distribution of ion beams and conics below $8000 \mathrm{~km}, J$. Geophys. Res., 86, 83, 1981.

Gurgiolo, C., and J. L. Burch, DE 1 observations of the polar windA heated and unheated component, Geophys. Res. Lett., 9, 945, 1982.

Hardy, D. A., J. W. Freeman, and H. K. Hills, Double-peaked ion spectra in the lobe plasma: Evidence for massive ions?, J. Geophys. Res., 82, 5529, 1977.

Heelis, R. A., and W. B. Hanson, High latitude ion convection in the nighttime $F$ region, $J$. Geophys Res., 85, 1995, 1980.

Heelis, R. A., J. D. Winningham, M. Sugiura, and N. C. Maynard, Particle acceleration parallel and perpendicular to the magnetic field observed by DE 2, J. Geophys. Res., 89, 3893, 1984.

Hultqvist, B., On the origin of the hot ions in the disturbed dayside magnetosphere, Planet. Space Sci, 31, 1973, 1983.

Johnson, R. G., Energetic ion composition in the earth's magnetosphere, Rev. Geophys. Space Phys., 17, 696, 1979.

Kintner, P. M., M. C. Kelley, R. D. Sharp, A. G. Ghielmetti, M. Temerin, C. Cattell, P. F. Mizera, and J. F. Fennell, Simultaneous observations of energetic (keV) upstreaming and electrostatic hydrogen cyclotron waves, J. Geophys. Res., 84, 7201, 1979.

Klumpar, D. M., Transversely accelerated ions: An ionospheric source of hot magnetospheric ions, J. Geophys. Res., 84, 4229, 1979.

Klumpar, D. M., Transversely accelerated ions in auroral arcs, in Physics of Auroral Arc Formation, Geophys. Monogr. Ser., vol. 25, edited by S.-I. Akasofu and J. R. Kan, p. 122, AGU, Washington, D. C., 1981.

Knudsen, W. C., Magnetospheric convection and the high-latitude F2 ionosphere, J. Geophys. Res., 79, 1046, 1974.

Lennartsson, W., E. G. Shelley, R. D. Sharp, R. G. Johnson, and H. Balsiger, Some initial ISEE-1 results on the ring current compositions and dynamics during the magnetic storm of December 11, 1977, Geophys. Res. Lett., 6, 483, 1979.

Lennartsson, W., R. D. Sharp, E. G. Shelley, R. G. Johnson, and H. Balsiger, Ion composition and energy distribution during 10 magnetic storms, J. Geophys. Res., 86, 4628, 1981.

Lockwood, M., Thermal ion flows in the topside auroral ionosphere and the effects of low-altitude, transverse acceleration, Planet. Space Sci., 30, 595, 1982.

Lockwood, M., Thermospheric control of the auroral source of $\mathrm{O}^{+}$ ions for the magnetosphere, J. Geophys. Res., 89, 301, 1984.

Lockwood, M., and J. E. Titheridge, Ionospheric origin of magnetospheric $\mathrm{O}^{+}$ions, Geophys. Res. Lett., $8,381,1981$.

Lockwood, M., A. D. Farmer, H. J. Opgenoorth, and S. R. Crothers, EISCAT observations of plasma convection and the high latitude, winter $F$-region during substorm activity, J. Atmos. Terr. Phys., 46, 489, 1984.

Lundin, R., L. R. Lyons, and N. Pissarenko, Observations of the ring current composition at $L 4$, Geophys. Res. Lett., 7, 425, 1980. 
Lundin, R., B. Hultqvist, E. Dubinin, A. Zackarov, and N. Pissarenko, Observations of outflowing ion beams on auroral field lines at altitudes of many earth radii, Planet. Space Sci., 30, $715,1982 a$.

Lundin, R., B. Hultqvist, N. Pissarenko, and A. Zackarov, The plasma mantle: Composition and other characteristics observed by means of the PROGNOZ-7 satellite, Space Sci. Rev., 31, 247, $1982 b$.

Moore, T. E., Modulation of terrestrial escape flux composition (by low-altitude acceleration and charge exchange chemistry), J. Geophys. Res., 85, 2011, 1980.

Moore, T. E., C. R. Chappell, M. Lockwood, and J. H. Waite, Jr., Suprathermal ion signatures of auroral acceleration processes, J. Geophys, Res., 90, 1611, 1985.

Nagai, T., J. H. Waite, Jr., J. L. Green, and C. R. Chappell, First measurements of supersonic polar wind in the polar magnetosphere, Geophys. Res. Lett., 11, 669, 1984.

Peterson, W. K., E. G. Shelley G. Haerendel, and G. Paschmann, Energetic ion composition in the subsolar magnetopause and boundary layer, J. Geophys. Res., 87, $2139,1982$.

Prange, R., Energetic (keV) ions of ionospheric origin in the magnetosphere: A review, Ann. Geophys., 34, 187, 1978.

Reiff, P. H., T. W. Hill, and J. L. Burch, Solar wind plasma injection at the dayside magnetospheric cusp, J. Geophys. Res., 82, 479, 1977.

Rosenbauer, H., H. Grunwald, M. D. Montgomery, G. Paschmann, and $\mathrm{N}$. Schopke, HEOS 2 plasma observations in the distant polar magnetosphere: The plasma mantle, J. Geophys. Res., 80, 2723,1975 .

Sharp, R. D., W. Lennartsson, W. K. Peterson, and E. Ungstrup, The mass dependence of wave particle interactions as observed with the ISEE 1 energetic ion mass spectrometer, Geophys. Res. Lett., 10, 651, 1983.

Shelley, E. G., D. L. Carr, W. K. Peterson, and R. D. Sharp, Sa tellite observations of energetic heavy ions during a geomagnetic storm, J. Geophys. Res., 77, 6104, 1972.
Shelley, E, G., R. D. Sharp, and R. G. Johnson, $\mathrm{He}^{++}$and $\mathrm{H}^{+}$flux estimates in the dayside cusp: Estimates of convection electric field, J. Geophys. Res., 81, 2363, 1976.

Shelley, E. G., W. K. Peterson, A. G. Ghielmetti, and J. Geiss, The polar ionosphere as a source of energetic magnetospheric plasma, Geophys. Res. Lett., 9, 941, 1982.

Singh, N., and R. W. Schunk, Numerical calculations relevant to the initial expansion of the polar wind, J. Geophys. Res., 87, 9154, 1982.

Sojka, J. J., W. J. Raitt, and R. W. Schunk, Plasma density features associated with strong convection in the winter high latitude F region, J. Geophys. Res., 86, 6908, 1981.

Waite, J. H., Jr., T. Nagai, J. F. E. Johnson, C. R. Chappell, J. L. Burch, T. L. Killeen, P. B. Hays, G. R. Carignan, W. K. Peterson, and E. G. Shelley, Escape of suprathermal $\mathrm{O}^{+}$ions in the polar cap, J. Geophys. Res., 90, 1619, 1985.

Yau, A. W., B. A. Whalen, W. K. Peterson, and E. G. Shelley, Distribution of upflowing ionospheric ions in the high-altitude polar cap and auroral ionosphere, J. Geophys. Res., 89, 5507, 1984.

Young, D. T., H. Balsiger, and J. Geiss, Correlations of magnetospheric ion composition with geomagnetic and solar activity, J. Geophys. Res., 87, 9077, 1982.

C. R. Chappell, T. E. Moore, and J. H. Waite, Jr., Space Science Laboratory, NASA Marshall Space Flight Center, Huntsville, AL 35812.

J. F. E. Johnson, Physics Department, University of Southampton, Southampton, SO9 5 NH, England.

M. Lockwood, Rutherford Appleton Laboratory, Chilton, OX11 0QX, England.

(Received July 9, 1984;

revised November 28, 1984;

accepted November 29,1984 .) 